تقويم جودة الخدمات التعليمية يُ كلية التربية بجامعة الدمام باستخدام مقياس (SERVQUAL)

خالد بن حسن الشغيبي * ومحمد سرحان خالد المخلاِيْ

جامعة الدمام، المملكة العربية السعودية

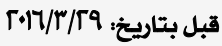

عدل بتاريخ:

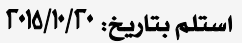

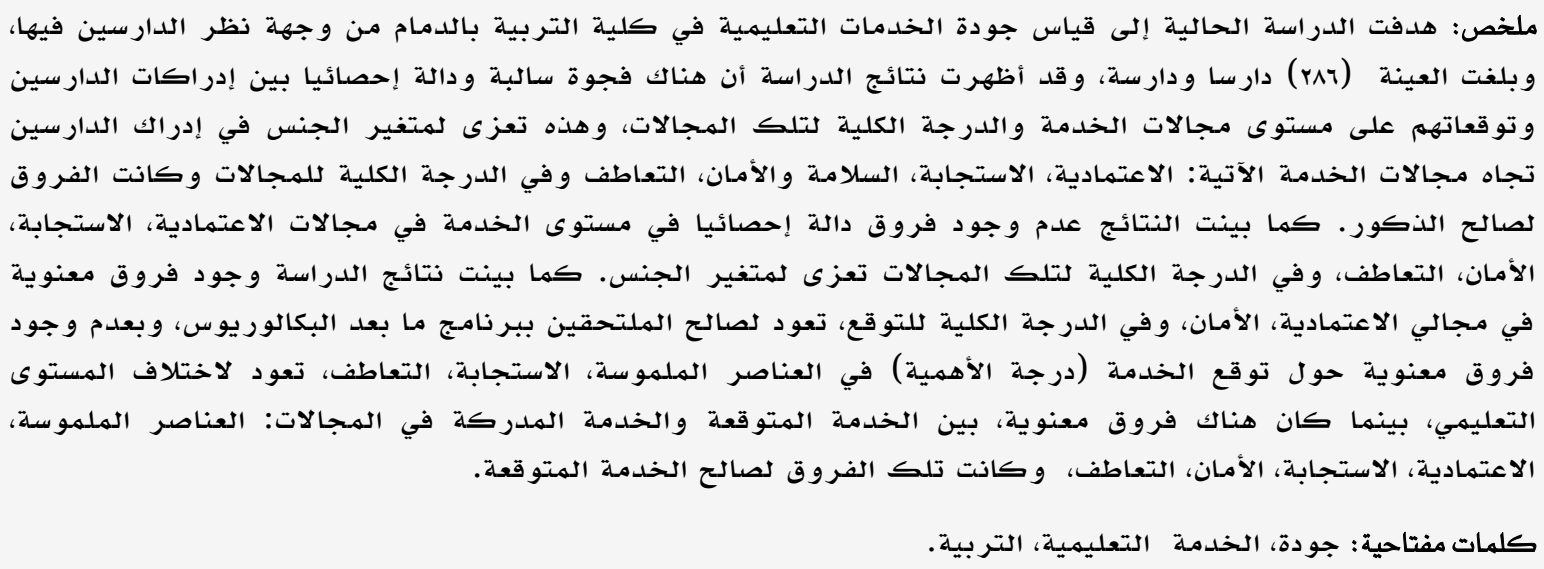

\title{
Quality Assessment of Educational Services in the College of Education, University of Dammam, Using (SERVQUAL) Scale
}

\author{
Khalid H. Al-shughibi* Mohammed S. Al-mekhlafie \\ University of Dammam, Kingdome of Saudi Arabia
}

\begin{abstract}
The study aimed at measuring educational services quality at the College of Education in Damam as perceived by students. For this purpose a sample of 286 students was selected randomly. The findings revealed overall negative statistical significant gap between students perception and expectation and the different service levels/dimensions. The study also showed negative statistical significant gap attributed to gender in their overall perceptions towards the areas: reliability, responsiveness, safety, empathy, in favor of males. The study also showed no significant differences attributed to gender in the students overall expectation of the educational services and in the areas reliability, responsiveness, safety and empathy. In addition, there were significant differences among the students expectations of the services in overall the moral aspects in favor of those enrolled at the post B. Ed program and no significant differences among them in the degree of importance in the tangible aspects such as responsiveness and empathy attributed to their educational level; whereas there were significant differences in the overall and in the moral aspects between the views of the expected and the perceived services in the overall and the areas tangible aspects, reliability, responsiveness, safety and empathy, in favor of the expected services.
\end{abstract}

Keywords: Quality, teaching service, education.

*dr.sarhan2011@gmail.com 
إن تطبيق الجودة في برامج الجامعات و منها كليات التربية تؤدي إلى خفض التكاليف و تمكن الإدارة من دراسـة احتياجات الهستفيدين والدونياء

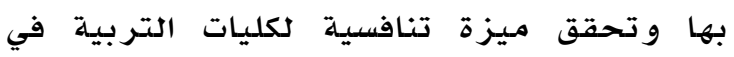
المجتهـع العلهي، في ظل الظروف التتافسية التي

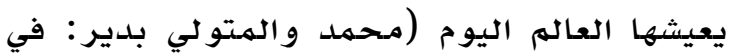

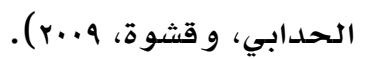

إن سعي الجامعة لتقديم خدمـة تعليمية ذات جودة عالية تلبي حاجات ورغبات الطلبـة الدارسين سيعزز بالتأكيد من العلاقة الإيجابية للطلبة في وريات الجامعة وزيادة و لائهم و وتشجيعهم بـالتأكيد لبقية الطلبة من معارفهم بالتسجيل في الجامعة ودهة

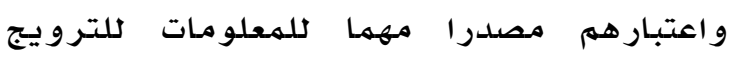

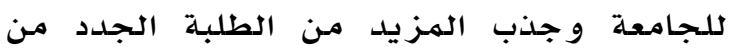

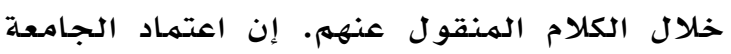

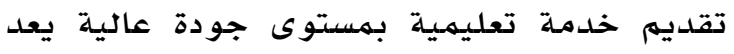
استراتيجية أساسية لتحقيق النجاح و البقاء وبناء

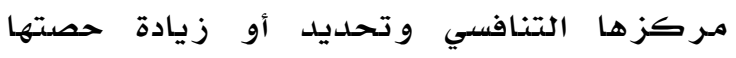
السوقية و تحقيق عائد مناسب للاستثمار وتقليل التكاليف في البيئة التنافسية في الوقتئ وقلت الحاضر وهو مـا أكدته العديد من نتائج الدراسـات في هذا

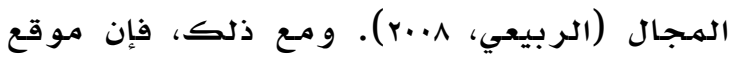

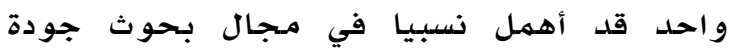
الخدمة ألا وهو التعليم العالي ( Shank, et al.,

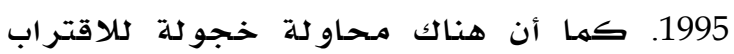
قليلا لتناول الجودة مـن وجهة نظر الطلاب

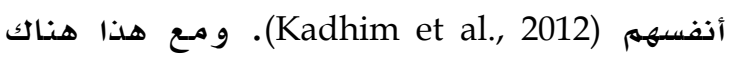
اهتمام متززايد في قياس جودة الخدمة في التعليم

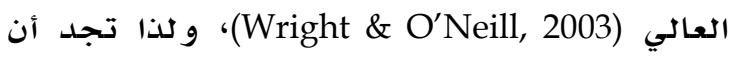
الباحثين الأكاديميين حريصون على قياس جودة الجدا

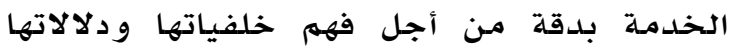
الأساسية، و من ثم وضع أساليب لتحسين جودتها (Palmer \& Cole, 1995)

\section{مفهوم جودة الخدمة}

عرفت الهو اصفة الدو لية 9000:2000 الجودة

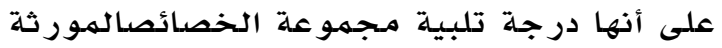

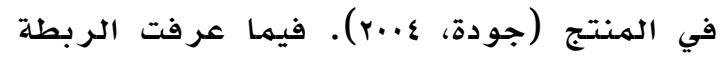

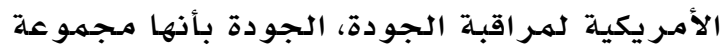

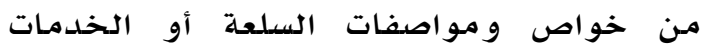

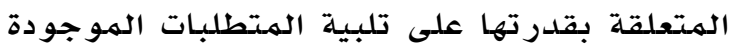

تواجه مؤسسات التعليهم العالي - في الدول المتقدمـة تحديات عديدة، نذكر في مقدمتها: تزايد حدة المنافسة بينها وتزايد أعداد الطلبة الطبة

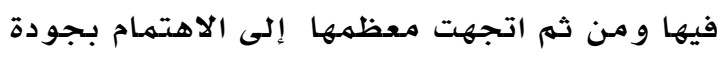

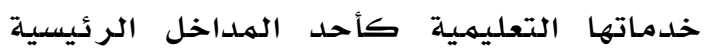

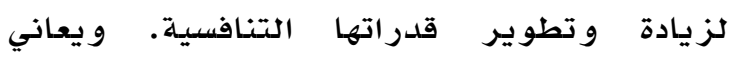
التعليم العالي في البلدان النامية من من مشاكل

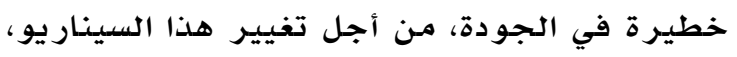

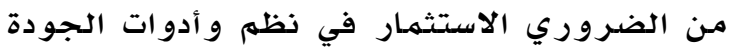

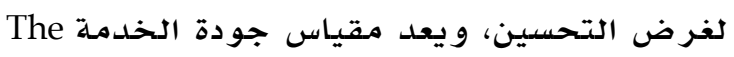
SERVQUAL scale

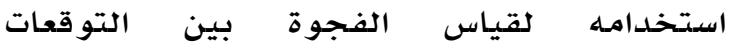

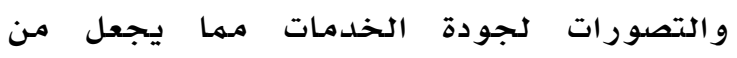
Otávio José المهمكن وضـع خطط عمل للتطوير (De Oliveira, 2011)

و تعد جودة التعليهم العالي أمرا أساسيا لتتـمية البلد؛ لأن الجامعات هي التي تعد المهنيين الذين

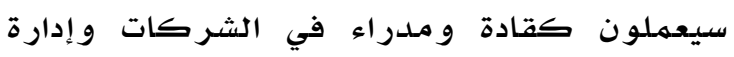

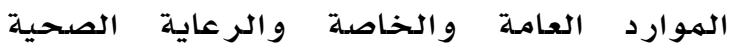
وتعليم الأجيال الجديدة (Oliveira, 2011). و على هذا الأساس ينظر إلى التعليم العالي على

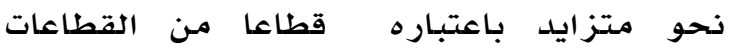

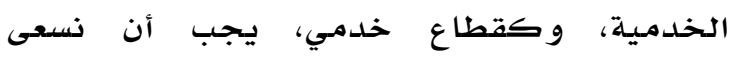
جاهدين لتحديد توقعات واحتياجات عملائه،

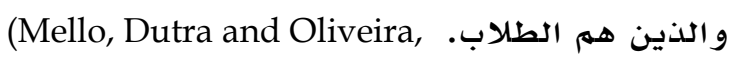

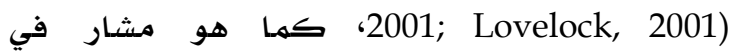
.(Otávio José De Oliveira, 2011)

و يحظى التعليهم في الهملكة العربية السعودية

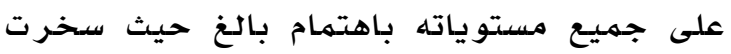

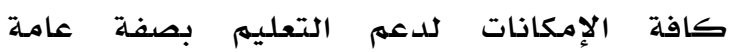
و التعليم العالي بصفة خاصة. والحقيقة أن أن الن الحة تحسين أداء المؤسسات بها فيها الجامعات

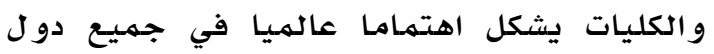
العالم، يضاف إلى ذلك أن قدرة أي مجتمـع على الى

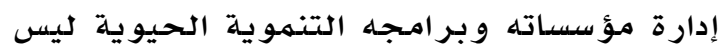
بالتركيز على فعالية هذه المؤسسات وكفاءتها

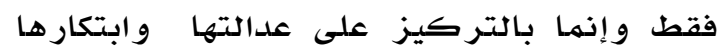
أيضسا، و مدىى مناسبـة بر امجها و خدماتها لتوقعات

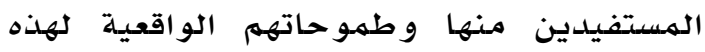
الخدمات. 
أبعاد الخدمات

يؤكس الباحث (Lovelock, 2002, p. 465) على أن لجودة الخدمة عشرة أبعاد أساسية هي الكفاية Reliability الجدارة) (Competence) والاعتمادة)

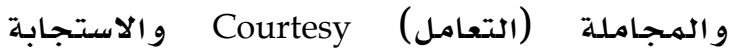
Responsiveness Security Understanding Customers و المصداقية Credibility و إمكان و سهو لة الحصول على م الخدمة Accessibility و والاتصالات Communication و التجسيد المادي Tangibility Service Quality جياس جودة الخدمة :Measurement من أهم نماذج قياس جودة الخدمة هو: نموذج الفجوة Gap Model / او ما يسمى مقياس جودة الخدمة ServeQual Scale: طور هذا النموذج عدد من الباحثين الأمريكان (1985, Parasuramann, Zeithaml and Berry

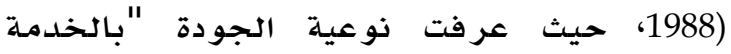

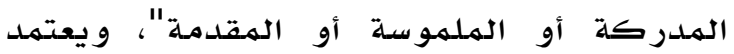

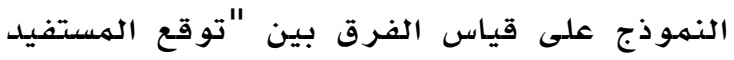

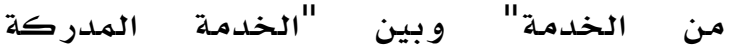

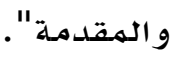

فيمثل نموذج جودة الخدمة ServeQual التباين

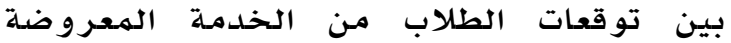
و تصوراتهم من الخدمة المقدمة, وما يسعى هذا النموذج إلى قياسه هو بالضبط إدرالك المستفيد

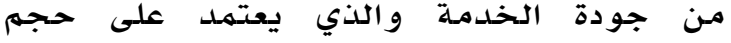
الفجوة بين الخدمة المتوقعة والخدمة المدركة و التي بدورها تعتمد على الفجوات التي تقع تحت

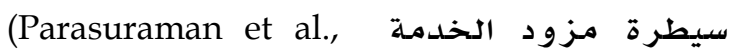

ويمكن التعبير عنها بالعبارة التالية: جودة

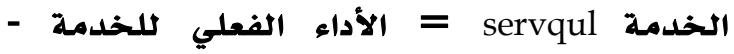
توقعات الطلاب. ويستند قياس جودة الخدمة على كيفية تقييم الطلاب عملية تقديم الخدمات و ونتائج الخدمة على حد سواء Parasuraman et) al., 1985, p.42)
أو المفتر ض وجودها فالجودة تحصل حين تقدم

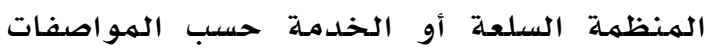

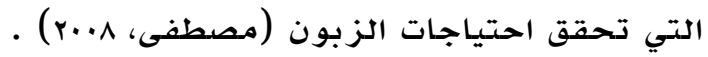
أما الخدمة فتعني كل فعل أو إجراء يمكن لطرف أن يقدمه لطرف آخر ويكون أساسا غير

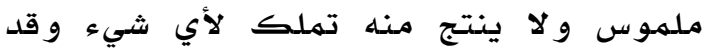
(Kotler, ير تبط أو لا ير تبط تقديمه بمنتج مادي منهائ

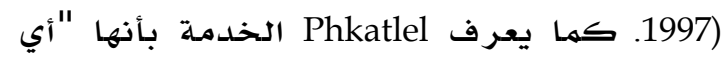
نشاط أو إنجاز أو منفعة يقدمها طرف ما لطرف

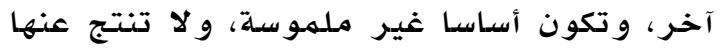

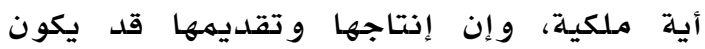

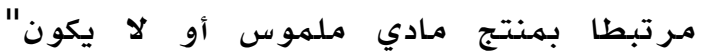

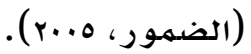

و تعرف جودة الخدمة بأنها معيار لدرجة تطابق

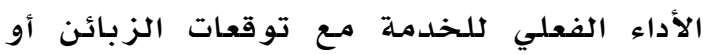
الفرق بين توقعات الزبائن و إدراكهم تلأداء الفعلي للخدمة (Hoffman, Bateson, 2011). ويعرف كل من (Krajewski \& Ritzman, 2000)

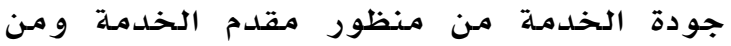

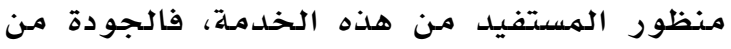

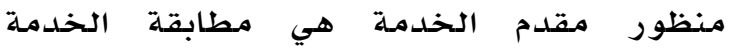

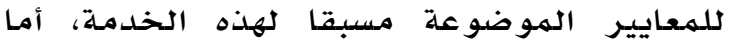
جودة الخدمة من منظور المستفيد (الزبون)

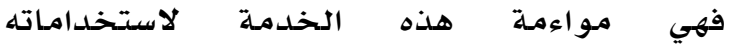

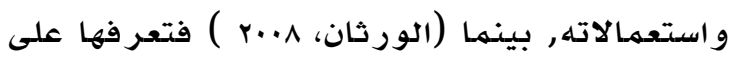

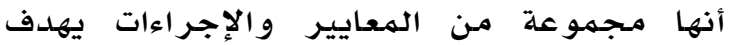

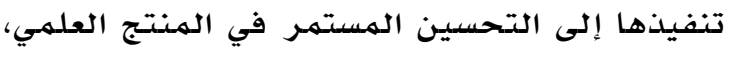

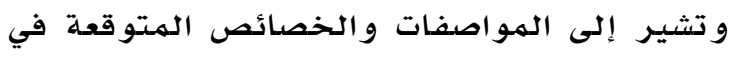
الخدمة التعليمية و في العمليات والأنشطة التي التئي

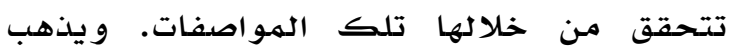

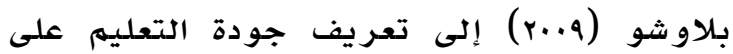

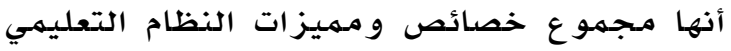
و مقدرته على تقديم منتج تعليمي مميز يلبي و يحقق الاحتياجات الآنية و المستقبلية والتطلعات

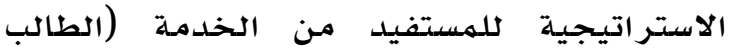
وسوق العمل و المجتهمع). 
رابعا: الأمان: شعور الطالب بالر احة والاطمئنان

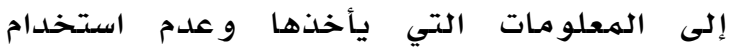
مصطلحات أو ألفاظ لا يفهمها وكذالكالك شعوره

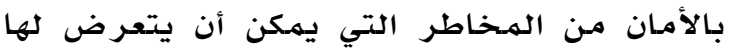
نتيجة سوء الخدمة وشعوره بالثقة، ومن الههم أيضا شعوره بأن العاملين أكفاء لهذه الخدهة

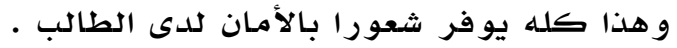
خامسا: التعاطف: أن يشعر الطالب أنه محور اهتمام الموظف وأن مصلحته هي الأسساس وأنه أنه

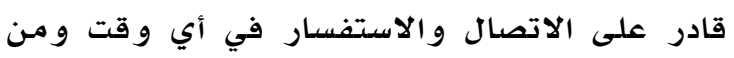
الضروري شعوره بأن المؤسسة تتفهـه حاجساته

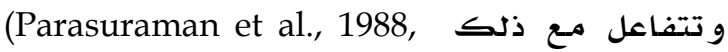

يعر ض شكل ا نموذج السير فكوال (SERVQUAL) لقياس الفجوة بين الخدمـة المتوقعة و المقدمـة.

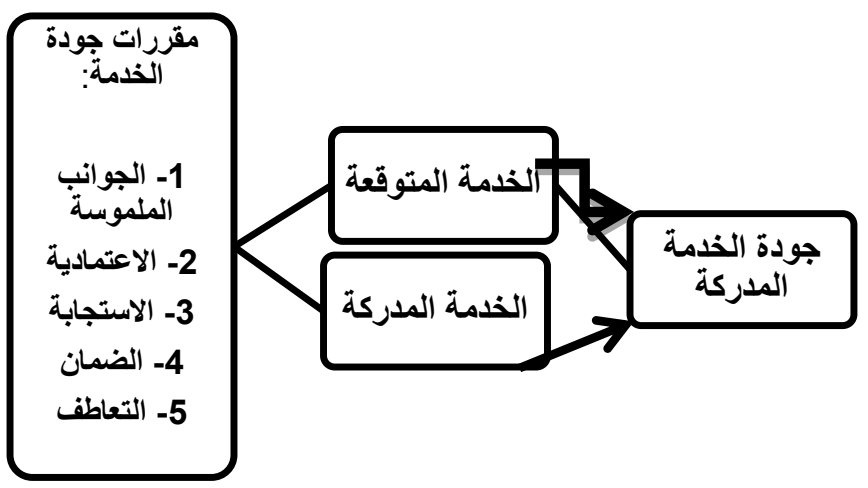

شكل 1

نموذج السيرفكوال (SERVQUAL) لقياس الفجوة بين الخدمة المتوقعة والمقدمة، (1988) Parasuraman et al.

ومن خلال الأبعاد الخمسة ىته التوصل إلى قياس الفجوة في أي بعد من تلك الأبعاد، كما يمكن من خلاله دراسـة أسباب الفجوات الخدئ الخمس.

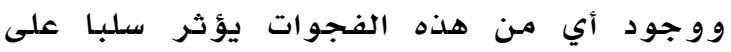

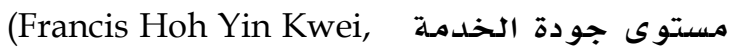
(2005، و هذه الفجو جودة ات هي: الفجوة الأولى: فجوة البحث Research Gap و هي الفرق بين توقعات الطلاب وتوقعات الإدارة. الفجوة الثانية: فجوة التصميم وهي الفرق بين إدراكات الإدارة لتوقعات الطلاب ومواتهفات

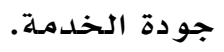

باعتبارها تلبي أو تتجاوز توقعات الهستفيد من الخدمة (Parasuraman et al. 1985, p.46). إن جودة الخدمة هي حاصل قسمة الأداء الفعلي للجودة على التوقعات, فإذا كانت الجودة إدها أكبر

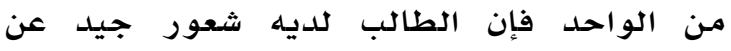
الخدمة التي يحصل عليها، و تكون نتائج المقارنة بين التوقعات والإدراكات على النحو التالي:

ا. Expected إذا كانت الجودة المتوقعة Quality Perceived Quality جودة الخدمة تكون أقل من مرضية، أي غير مقبو لة. Y. إذا كانت الجودة المتوقعة مساوية لجودة

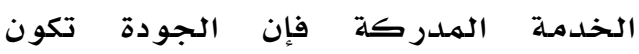

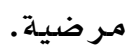
r. إذا كانت الجودة الهتوقعة أقل مـن الجودة

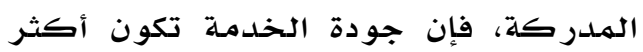

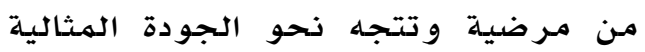

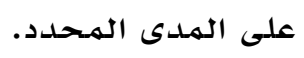

محددات جودة الخدمات في هذا النموذج تم تحديد خمسة محددات أو

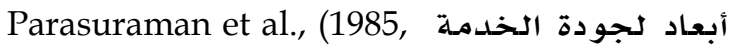

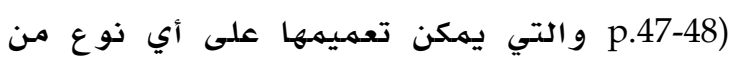

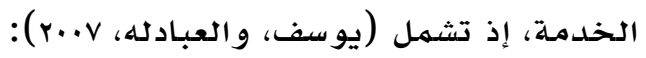

أولا: العناصر الملموسة: وهى تشمل جميع

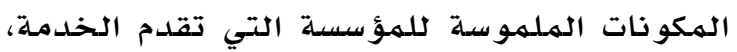
مثل الأدوات والآلات و المباني ومظهر الهور العاملين

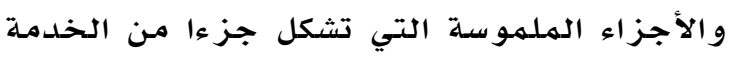

$$
\text { نفسها. }
$$

ثانيا: الاعتمادية: وهذا يعني الاعتماد على المؤسسة في قدر تها على تقديهم مستوى معين من الجودة كلما طلب منها ذلك أو بمعنى آخر ملهر

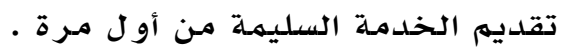
ثالثا- الاستجابة: وهذا يعني رغبة و واستعداد العاملين في المؤسسة التعليمية لتقديم الخحدمات و الرد على استفسارات الطلاب وتلبية طلباتهم في الوقت المحسد. 
التي تواجهها طالبات الجامعات السعودية أثناء

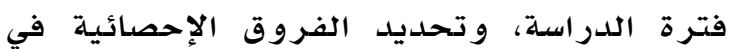

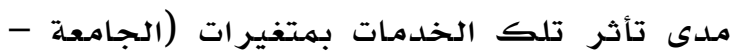

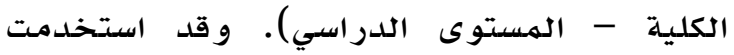
الدراسـة الهنهج الوصفي الهسحي لتحديد أهم الهم

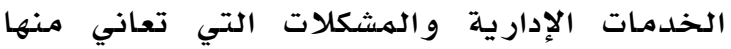
الطالبات من وجهة نظرهن ووكذلك علاقة هذه

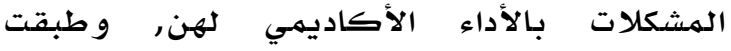

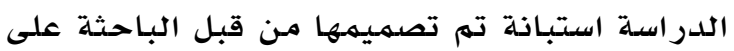
عينة عشوائية من طالبات جامعتي الأميرة نورة و الملك سعود في الرياض بلغ عددهن ·^ع طالبة تم اختيارهن باستخدام طريقة العينة العشوائية الطبقية. أظهرت الدراسة أن المشكلات المتعلقة

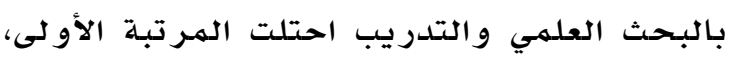

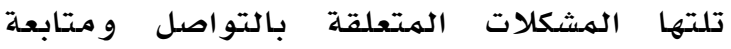
الخريجين، ثم المشكلات المتعلقة بالإرشاد

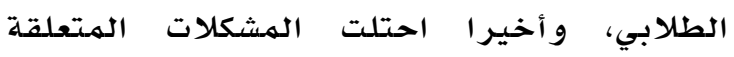
بالقبول والتسجيل المـرتبـة الأخيرة. و بناء على الى التيرل تلك النتائج توصلت الدراسـة إلى عدة توصيات منها ما هو موجه لالإدارة الجامعة ومنها ما هو موجه إلى أعضداء هيئة التدريس. أما دراسة كل من (محمد وخضر، سابr)، فقد

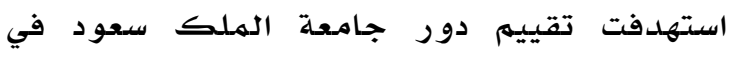
تقديم الخدمات التعليمية من خلال قياس جودة

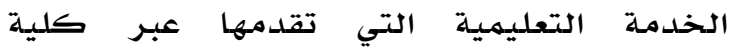

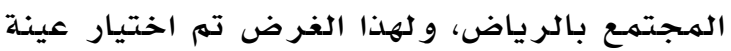

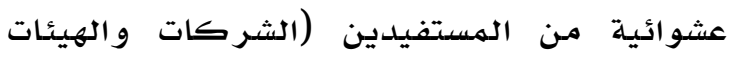

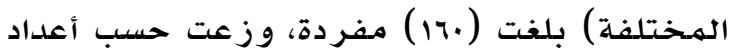
الخريجين الملتحقين بكل جهة. وقد وبقت الدراسـة مقياس الفجوة (SERVQUAL) لقياس الهين

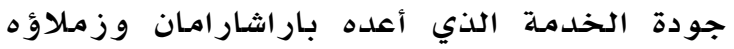
بعد تطويره ليناسب (Parasuraman et al., 1988) جودة الخدمة التعليمية في الجامعة ورتوصلت الدراسة إلى أن مستوى الخدمات التعليميلة غير مـر ضي. كما أجرى (البشري، rا.r)، دراسة وهدفت إلى

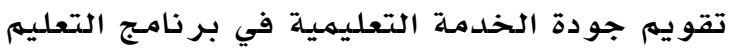

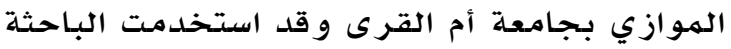
المنهج الوصفي المسحي لقياس آراء عينـة طبقية
Delivery Gap "الفجوة الثالثة: "فجوة التقديه و هي الفرق بين مواصفات جودة الخدمة و تسليم الخدمة.

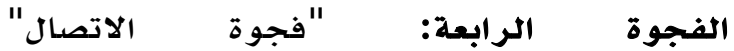
Communication Gap

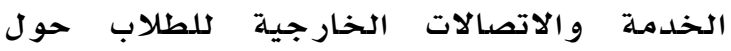

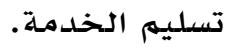

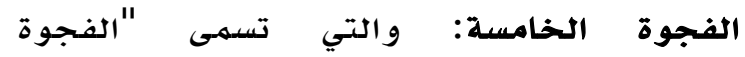
الحقيقية" Reality Gap و هي الفرق بين توقعات الطلاب للخدمة والخدمة الميه المدرركة (الفعلية) المسلمـة. شكل r يعر ض تلك الفجوات.

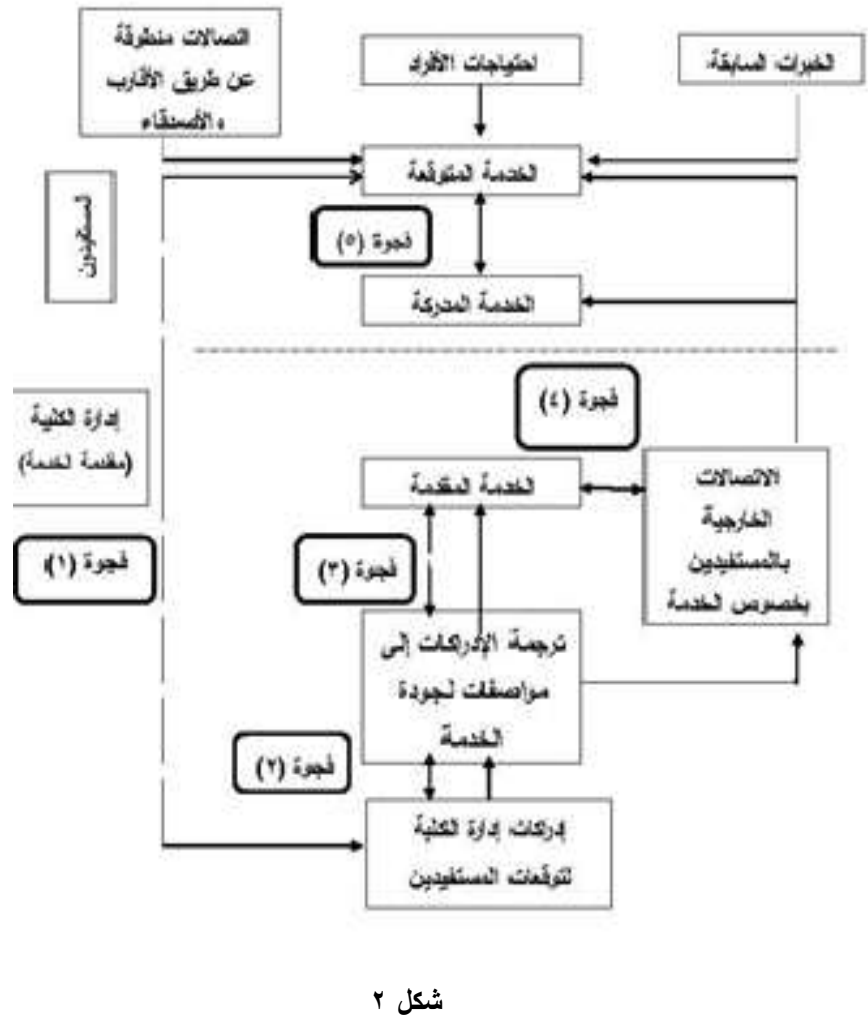

(Kumar et al, لقياس جودة الخدمة ERVQUAL model لموذج 2009)

و قد أجريت عدد مـن الدراسـات حول قياس جودة الخدمات التعليمية في عدد من الجامعات منها

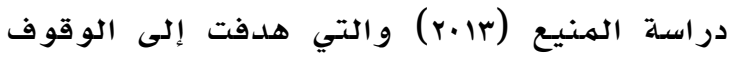

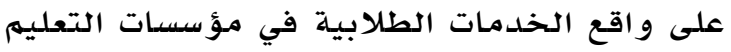
العالي في المهملكة العربية السعودية من وجهة نظر الطالبات، وتحديد أهم المشكاتلات الطلابية 


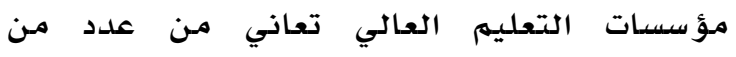

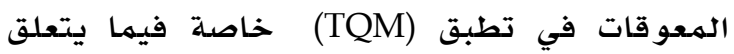
بجودة الخدمات التعليمية.

تلك دراسة الحدابي، وقشوة (q.....)، وهدفت

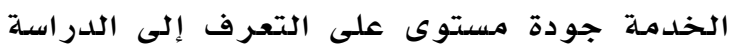

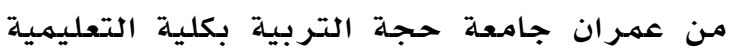

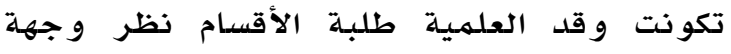

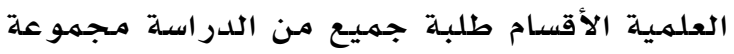

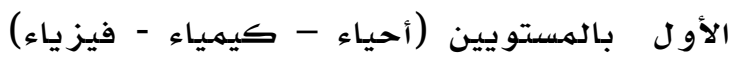

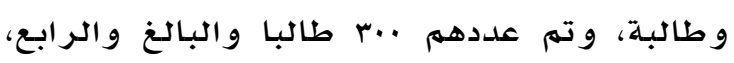

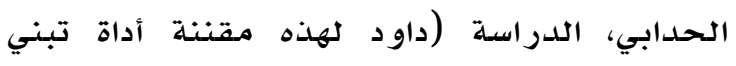

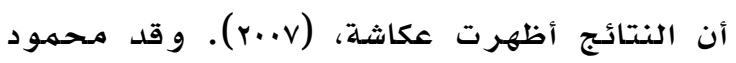

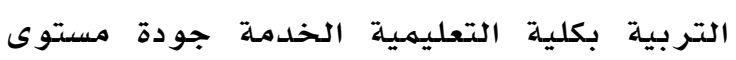

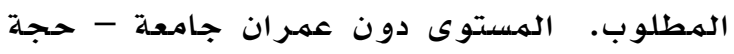

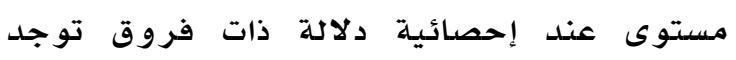
التعليمية الخدمة جودة لهستوى (0.05) الدلادية لمتغيري التخصص والمستوى و الجنس. تعزى الجى الموديه

و تسعى الدر اسـة الحالية إلى معرفة مستوى جودة

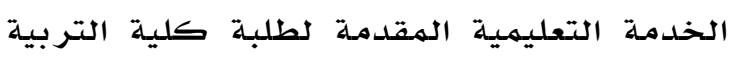
بالدمام - جامعة الدمام في جميع مستوية الدياته

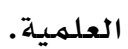

مشكلة الدراسة

يعد الطلاب في مجال التعليم العالي، الزبائن

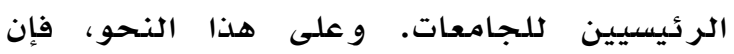
توفير خدمات عالية الجودة وإثباع احتياجات

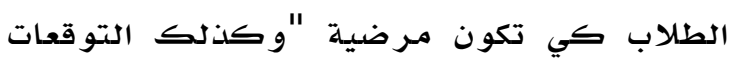

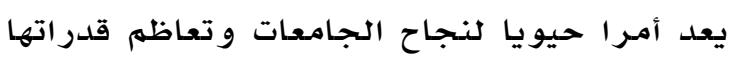

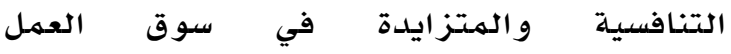
(Farahmandian, 2013)

و لقد أحس الباحثان أن هناك عدم رضا لدارسي

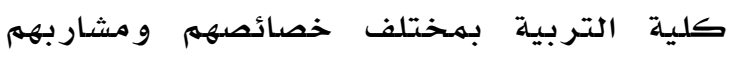

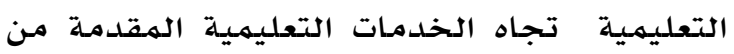

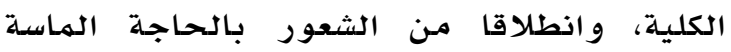

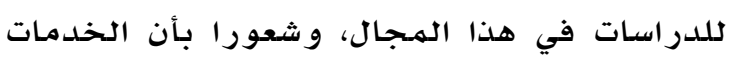

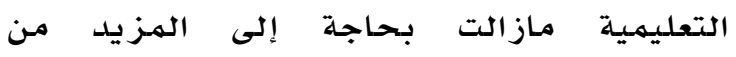

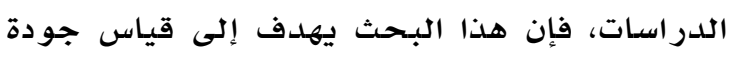

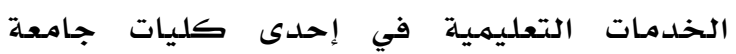

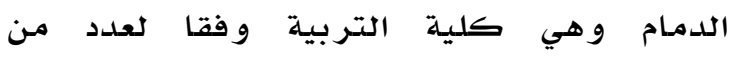

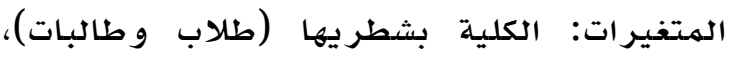

عشوائية مـن طالبـات بر نامـج التعليم الموازي

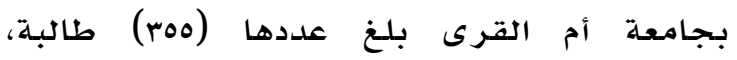

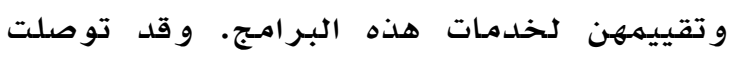

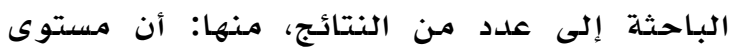

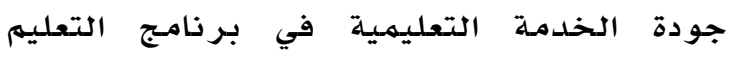
الموازي كان بلدرجة متوسطة، وجود فرودة فروق ذات

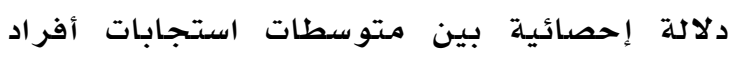

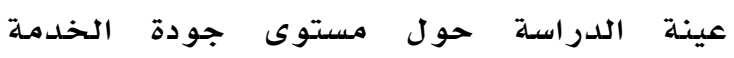

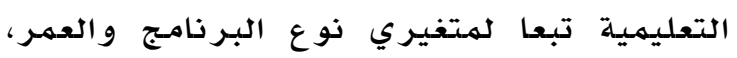
عدم وجود فروق ذات دلالة إحصائية حول لئرل

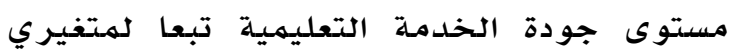
التخصص و الحالة الوظيفية. أما دراسلة حمدان (r.|r)، فقد هدفت إلى بيان

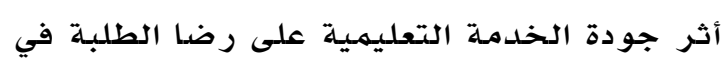

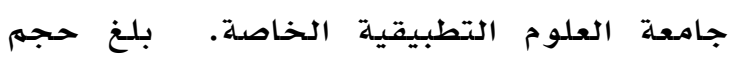
العينة 170 طالب وطالبة وقام الباحث بتصميه

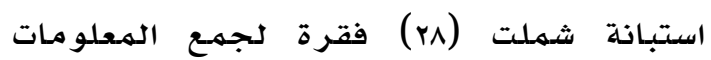

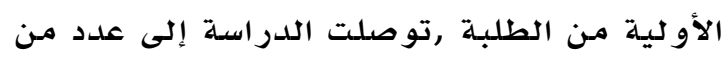

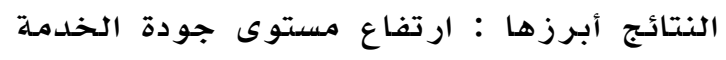
التعليمية و الذي انعكس في ارتفاع مستوى رضئ رضا

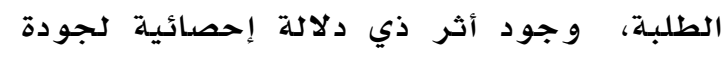

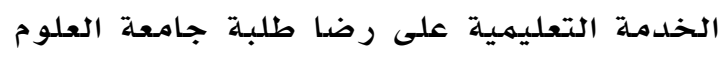
التطبيقية الخاصدة عند مستوى دلالة (05.).

(Chienh Hsiung W., كما أجريت دراسـة

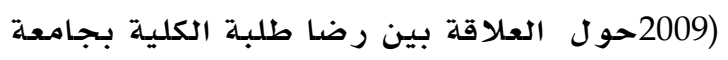

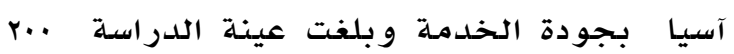

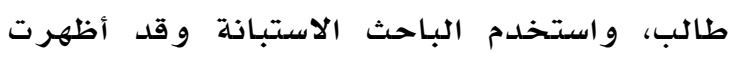

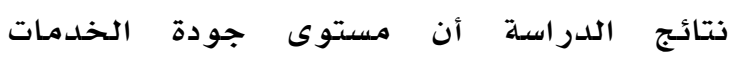

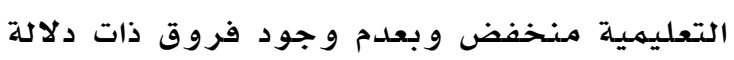

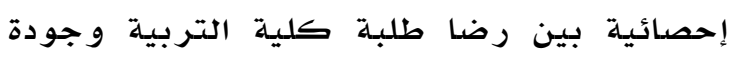

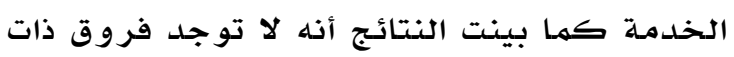

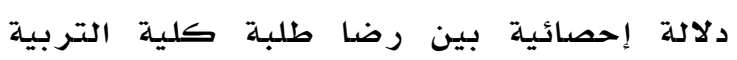
و جودة الخدمة.

و أجر يت در اسـة (Kolinski John, K., 2002) حول

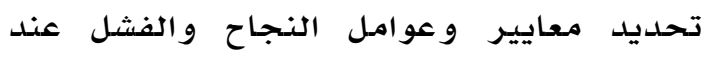

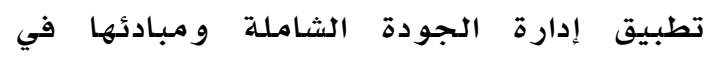

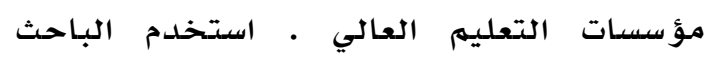
استمارة استبانة تم توزيعها على عينة مقدار هاريا

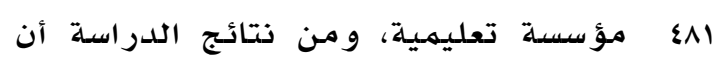


والذكور ) بجامعة الدمام و فقا للجنس

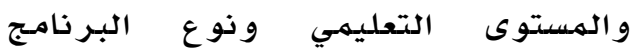

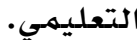

r إفادة المسؤولين عن الكلية و المهتمين

بتخطيط وتطوير الخدمات للمستفيدين

منها طلابا و باحثين و أساتذة.

r. مد بعض أوجه النقص في الدراسات

المتعلقة بجودة الخدمات التعليمية بكليات

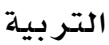

؟.التعرف على الفروق الجوهرية بين

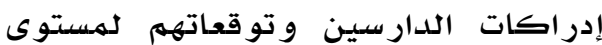
مجالات وعناصر الخدمات المقدمة في الديات كلية التربية بجامعة الدمام.

\section{أهمية الدراسة}

تعتبر الخدمات التعليمية أحد أنواع الخدمات الأودات

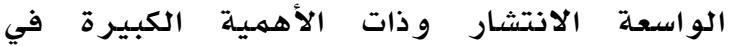

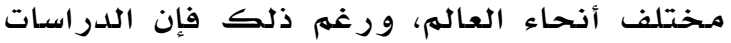
و الأبحاث التي تناقش جودة الخدمات التعليمية

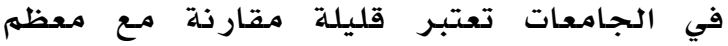
خدمات الأنشطة الأخرى (عاشور، و العبادله، أمهي

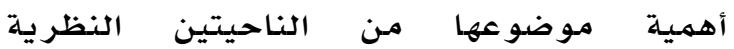
والتطبيقية؛ فمن الناحية النظرية تعتبر هذهائه

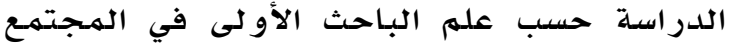

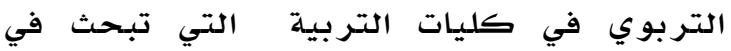
معايير جودة الخدمات التي تقدمها تلك الكلية باستخدام أسلوب الفجوة بين مدرركات وتوقعات

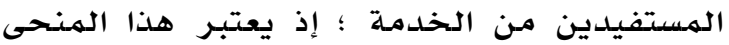
هو المنحى الأحدث في عالم إدارة الجودة لهادئ الشاملة لتقييم الخدمة في مناحي الحادي الحياة

الهـختلفة.

أما من الناحية التطبيقية فتبرز أهمية هذه

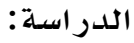

ا. في تعبيرها عن مستوى جودة الخدمات المقدمة من قبل كلية التربية لطلابها، و مدى توافقها مـع رغباتهم وحاجاتهم، وذلك من أجل تشخيص مستوى جودة الخدمات المقدمة من قبل اجل الكلية، ورفع
المستوى التعليمي، مستوى البرنامج التعليمي كنموذج للكليات الأخرى التابعة للجامعة. و وعليه فإن مشكلة الدراسة تتبلور في الآتي: إن التعرف على مستوى جودة الخدمات التعليمية

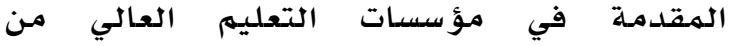
وجهةنظر زبائنها، بهدف التماس جوانب القوة و القصور فيها والعهل على تطوير ها، هو الضمان

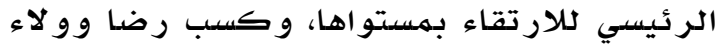
الزبائن لها. وونظرا لغياب تقييم جودة الخدمات التعليمية في الكلية فإن هناك حاجة لتقييمطلاب

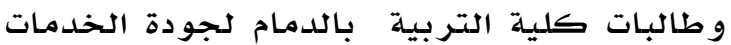
التعليمية المقدمة إليهم بشكل عام، وكذا وفقاليا

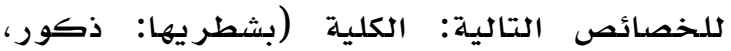

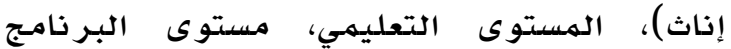
التعليمي.

و عليه فإن الدراسة تسعى للإجابة عن الأسئلة

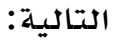

1. هل توجد فروق ذات دلالة إحصائية عند

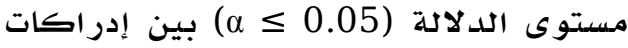

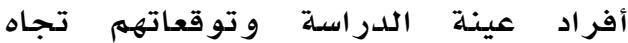
مستوى عناصر الخدمات المقدمة من قبل كلية التربية بالدمام ؟ r. هل توجد فروق ذات دلالة إحصائية عند

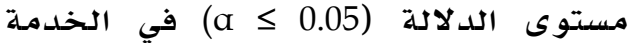

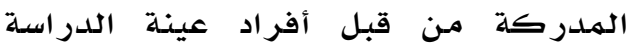
وتوقعاتهم لهذه الخدمة تعزى لمتغير الفرال

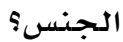

r. مل توجد فروق ذات دلالة إحصائية عند

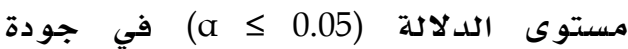
الخدمة التعليمية المدركة من قبل أفراد

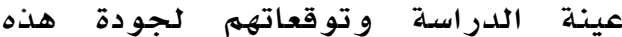
الخدمة تعزى لمتغير المستوى التعليمي؟

أهداف الدراسة

تسعى الدراسة الحالية بالتحديد إلى تحقيق

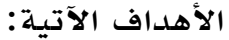

1. تحديد مستوى جودة الخدمة التعليمية المقدمة من كلية التربية (بشقيها: الإناث 


\section{تحديد مجتمع الدراسة وعينتها}

مجتمع الدراسة

يمثل مجتمع الدراسة جميع طلاب وطالبات

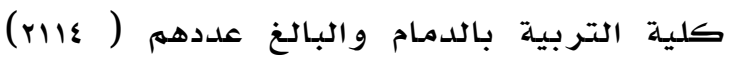

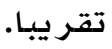

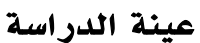

تكونت عينة الدراسة من ( برץ) طالبا وطالبة

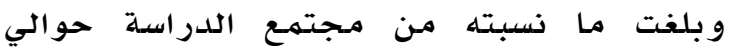

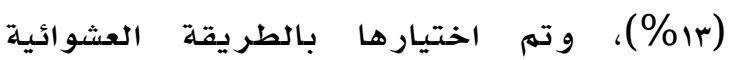

\section{التعريفات الإجر ائية}

جودة الخدمة التعليمية: Education Service

Quality

إن جودة الخدمة هي" معيار لدرجة تطابق الأداء

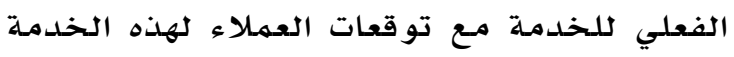
(Lewis \& Boom: 1983) خصائص ومميزات المنتج التعليمي على تلبية

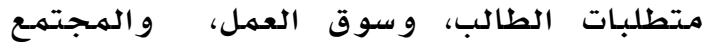
وكافة الجهات الداخلية والخارجية المنتفعة والية

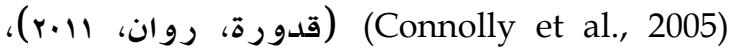
و تعني جودة الخدمة "الفرق بين توقعات العملاء

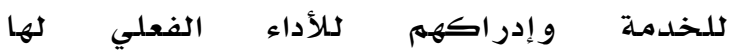

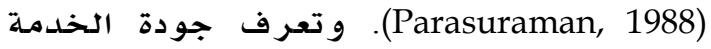

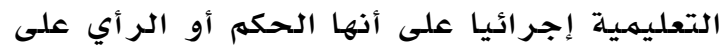

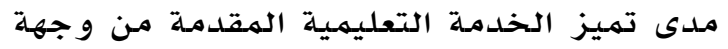
نظر الطلبة بالكلية، و لأغراض هذه الدها الدراسة فإنها تشمل خمسة أبعاد أساسية هي:

الملموسات، Tangible، الموثوقية، Reliability، و الاستجابة، الموثوقية

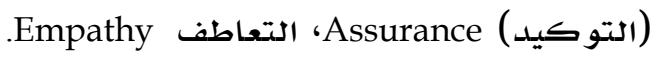
الفجوة بين الإدراكات perceptions والتوقعات: Expectation

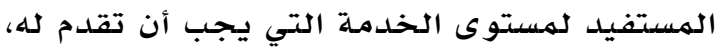

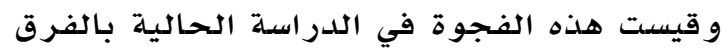
بين إدراك الدارسين و توقعاتهم باستخدام مقياس الفجوة (ServQual Gap) المطور عن مقياس Parasuraman \& Others, بار اشار امان وزملائه (1988 ليناسب قياس الخدمة التعليمة الجامعية.
مستو اها بما يحقق رغبات وحاجات الطلبة

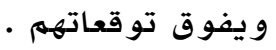

r. كما تنبع أهمية هذه الدراسة من اختيار

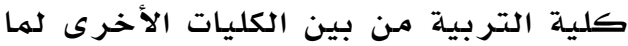

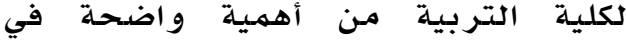
تأثيرها على التنمية والتطوير في مختلف

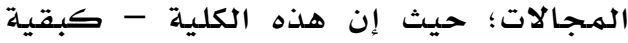
كليات التربية الأخرى- تعمل على إعداد النداد الادية التربويين المهتمين بتربية الأجيال المستقبلية والتي سيكون لها لالأثر الجوهري في كافة الميادين التربوية

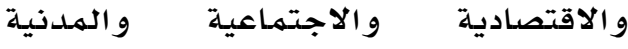
و والسياسية في البلد.

\section{حلدود الدر اسة} اقتصرت الدراسة على:

1. المجال البشري: آراء طلبة الأقسام العلمية والإنسانية في سنة الأساس والدية الديبلو الإمات الدات

والدراسات العليا بكلية التربية بالدمام - والداية

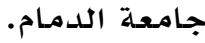

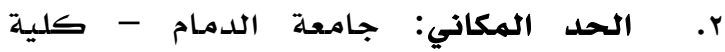
التربية (بشقيها: الذكور وامعة الإناث)

r. المجال الزمني: تم تطبيق هذه الدراسة

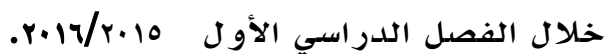

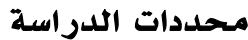

تحدد نتائج هذه الدراسة جزئيا أو كليا بالأدوات

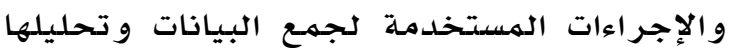

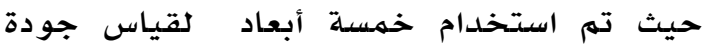

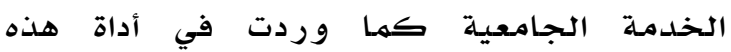

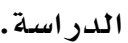

\section{الطريقة والإجر اءات}

اتبعت الدراسة المنهج الوصفي في معرفة آراء

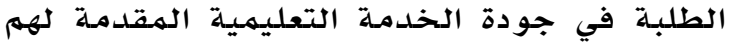
من قبل الكلية وقد تم تبني أداة مقننة لهذا

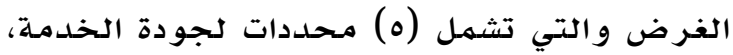

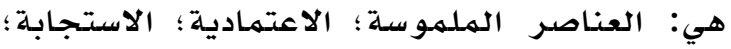
الأمان؛ التعاطف، و عدد فقر اتها (19) فقرة . 
وأكثر من مرضية وبالتالي تتجه نحو الامتياز

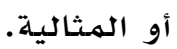

تحديد اتجاه آراء العينة حول متغيرات الدراسة

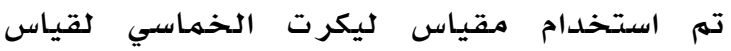

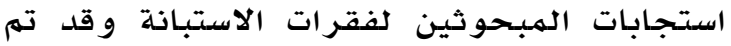

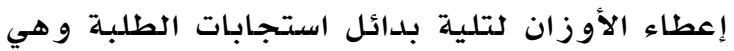

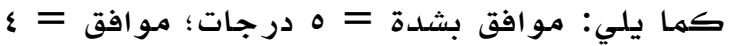

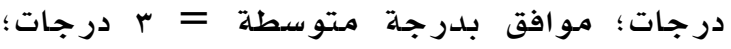
غير موافق = r درجتين؛ غير موافق بشدة مداتوسة

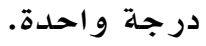

\section{تصحيح قيم الأداة}

تم حساب المتوسط الحسابي المرجح الابحساب ليتهم تحديد الاتجاه حسب قيم المتوسط الحس المرجح من خلال تصحيح المديات كما يلي:

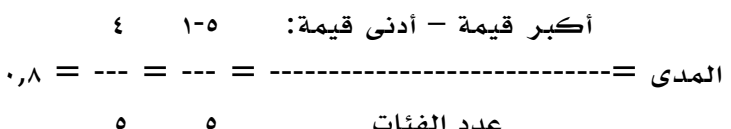
و تصبح نتيجة التصحيح كما يلي:

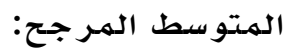

غير موافق بشدة. غير موافق. - مئ موافق بدرجة متوسطة.

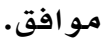

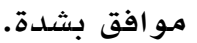
(إلى

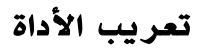
تمت عملية تطوير أداة الدراسة وفقا للخطوات

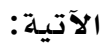

1. قام الباحث بترجمة المقياس من لغته

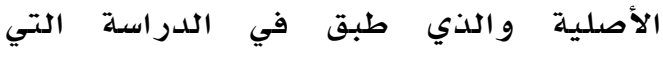

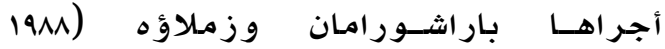
(Parasuraman, \& Others, مجالات تحتوي على (rr) عنصرا من عناصر

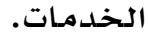

r. عرض المقياس بصورته الأولية على

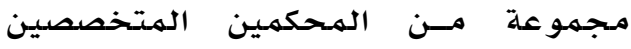

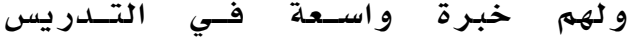

أدوات الدراسة (أسلوب جمع البيانات و أدوات

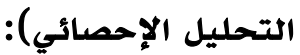

كون البحث الحالي يقوم على قياس الفجوة الرئيسة و محدداتها، فقد تم الاعتماد على أنموذج الجي Service Quality Model

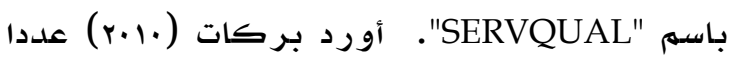

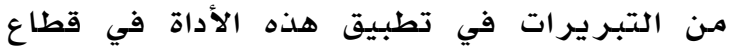

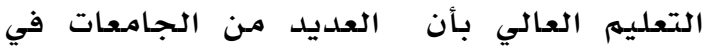
العالم قد استخدمت هذا المقياس للتعرف على التى إدارة الجودة الشاملة في خدماتها التعليمية

\section{الهـختلفة.}

تم جمع البيانات اللازمة من خلال ق قائمة

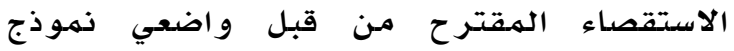

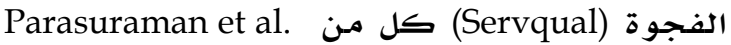

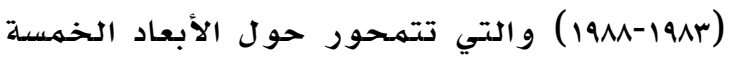

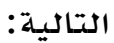

ا. الأشياء المحسوسة أو الملموسة Tangibles

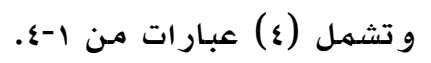

r. Reliability و وتشمل (ع)

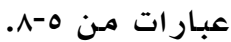

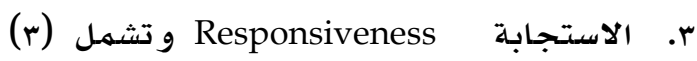

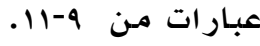
ع. الثقة

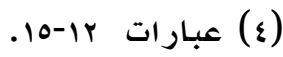

ه. التعاطف Empathy وتشمل (ع) عبارات

$.19-17$

و تنقسم الأداة على قسمين: الأول يقيس توقعات

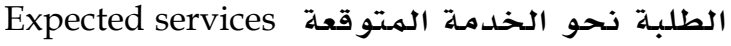
والقسم الثاني: يقيس إدراكات الطلبة لجودة

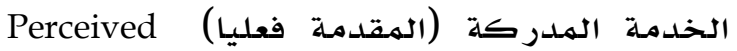
services الفرق بين الإدراكات و التوقعات (Q=P-E) فإذاذ كانت إدراكات الطلاب لجودة الخدمة المقدمة أقل من توقعاتهم تكون الجودة منخفضة، وإذا إذا

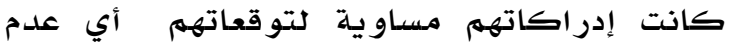

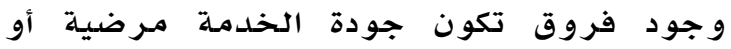

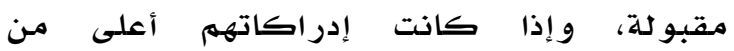

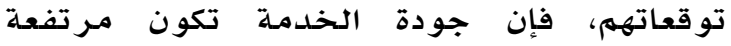




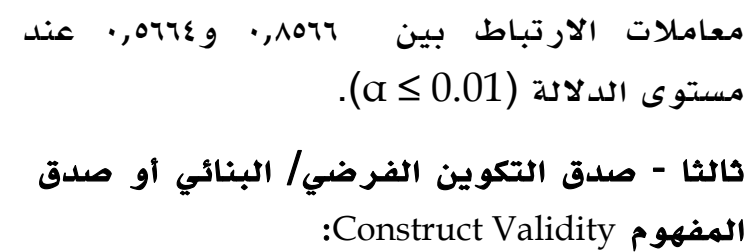

معاملات ارتباط بيرسون لقياس العلاقة بين مجالات الاستبانة، بالدرجة ارتباط الكلية للأداة: لمعرفة مدى ارتباط كل مجال من مجالات

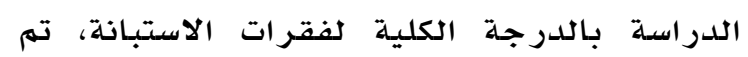

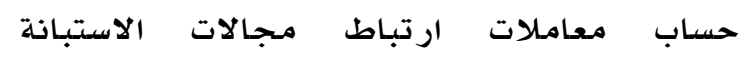
بالدرجة الكلية للأداة ارتباط (العينة الاستطلاعية:

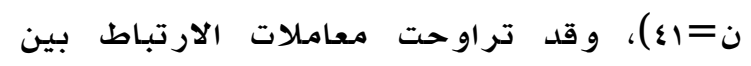
و

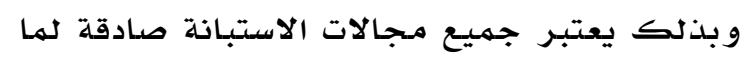
وضع لقياسـه.

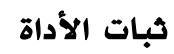

تحقق الباحث من ثبات استبانة الدراسة من خلال الآتي: تحقي

Cronbach's Alpha معامل الفا كرونباخ :Coefficient

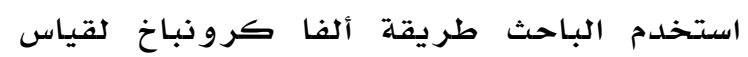

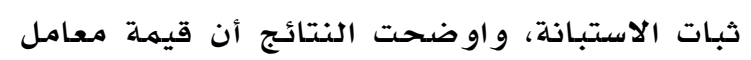

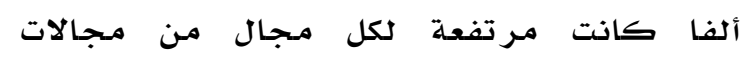

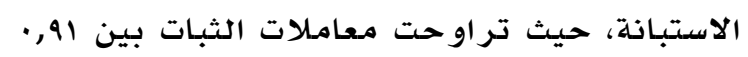

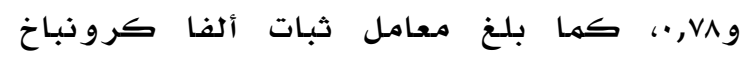

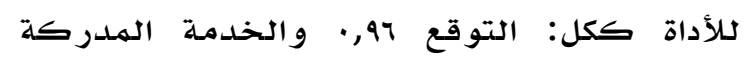
$\therefore$, व

\section{المعالجة الإحصائية}

لتحليل البيانات إحصائيا تم اعتمـاد:

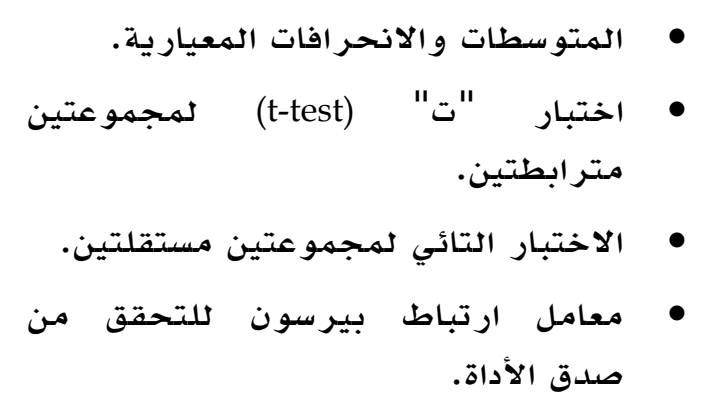

الجامعي، طلب منهم للحكم على مدلى العنى

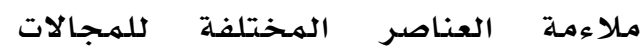

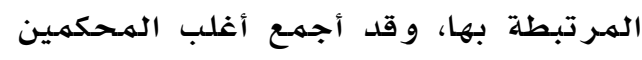

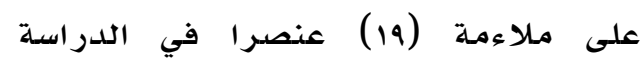
الحالية. - الماء.

صدق أداة الدراسة

للتأكد من أن المقياس الذي تم استخلدامه يقيس

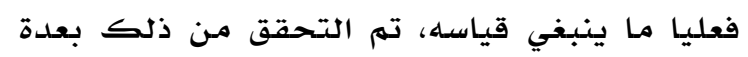
طرق: - معلي

أو لا الصدق الظاهري Face Validity:

إن أفضل طريقة للتأكد من الصدق الظاهري

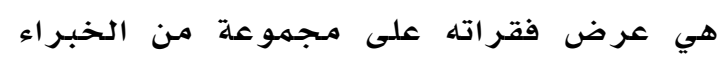

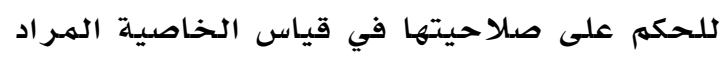

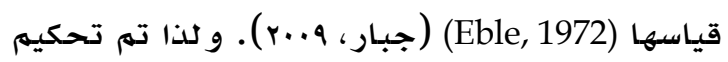

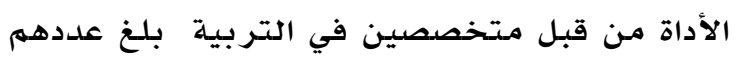

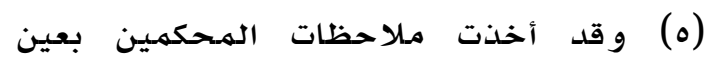
الاعتبار، و تم بعد ذلك الندات تطوير الاستبانة بشكلها

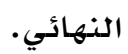
ثانيا الاتساق الداخلي Internal Validity: تم التحقق من توفر الاتساق الداخلي لكلأداة من

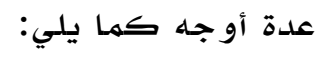

معاملات ارتباط بيرسون لقياس العلاقة بين بنود الاستبانة، بالدرجة الكلية للمجال المنتمية إليه: قام الباحث بحساب الاتساق الداخلي للاستبانة

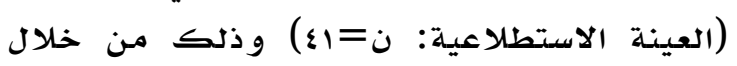

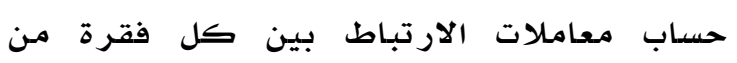

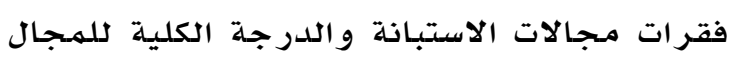

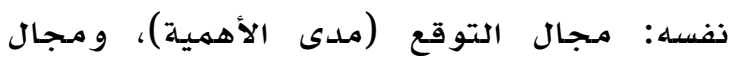

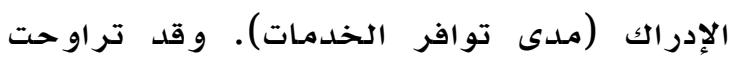

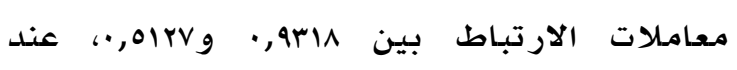

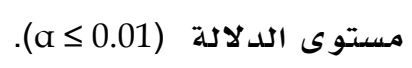

معاملات ارتباط بيرسون لقياس العلاقة بين بنود الاستبانة بالدرجة الكلية كلأداة:

تم حساب معاملات الارتباط لبنود الاستبانة:

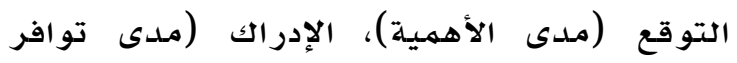

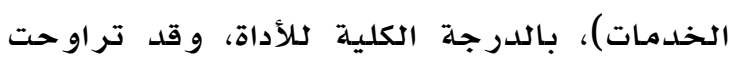


الدراسة وتوقعاتهم تجاه مستوى عناصر الخلدمات المقدمة من قبل كلية التربية بالدمامو ولهو

لكي يتهم الإجابة عن هذا السؤال تم حساب

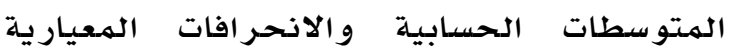
لدرجات إدراكات الدارسين و توقعاتهم تجهاه الخدمات التعليمية التي تقدمها كلية التربية

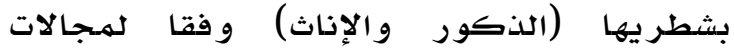
و عناصر تلك الخدمات، حيث تثير الفروقات

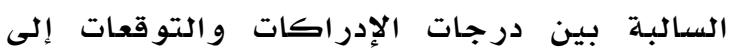
انخفاض في مستوى الخدمـة المقدمـة، بينما تشير

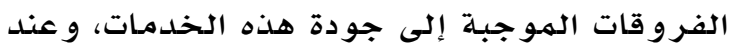
استخدام اختبار (ت) لمجموعوعتين متر ابطتين تم إنوده

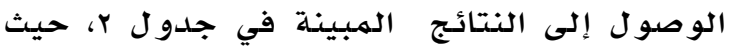
تشير تلك النتائج إلى أن تقييم الدئ الدارسين لمستوى جودة الخدمات التي تقدمها الكلية على إلى التهات

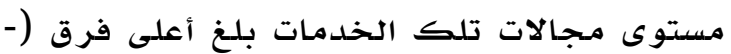

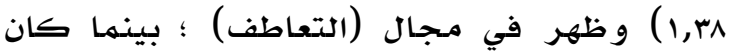
أقل فرق (-^ی,.•) قد ظهر في مجال (الأمان). بتطييق الاختبار الإحصائي (t-test) لبيان مدىى

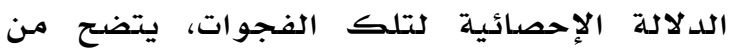

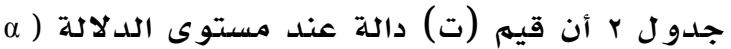

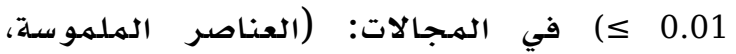
الاعتمادية، الاستجابة، الأمان، التعاطف)، و وفي

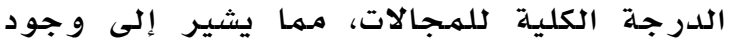
فروق (فجوة) ذات دلالة إحصائية في استجابات

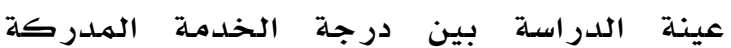
(الخدمة الفعلية)، والخدمة الندة المتوقعة (الأهميلة) في تلك المجالات، ووكانت تلك الفروق لصالح

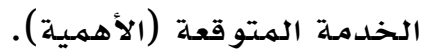

وكما هو الحال مـع مجالات الخدمـة، تشير

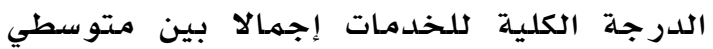
الإدراك والتوقع للدارسين إلى ضعف الكيه في مستوى الخدمات التعليمية المقدمة مـن الكلية بشطر يها. اما على مستوى الدرجة الكلية للخدمة المتوقعة

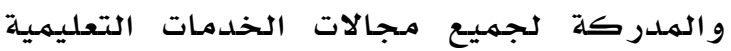

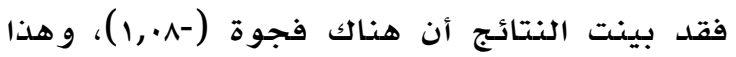
يعني أن مستوى جودة تقديم الخدمات التعليمية التيلية

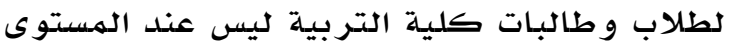

هما تهم استخدام معادلة كرونباخ لقياس درجة (Cronbach's Alpha)

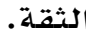

ثم تمت معالجة البيانات إحصائيا

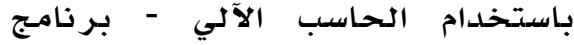
الحزمة الإحصائية (SPSS).

متغيرات الدراسة

أو لا :المتغير ات المستقلة وتشتمل: الجنس و له مستو يان: ذكور، و إناث.

طبيعة البرنامـج: وله مستويان: بكالوريوس، مـا بعد البكالور يوس.

ثانيا :المتغير التابع: وتتمثل بمتوسطات درجات

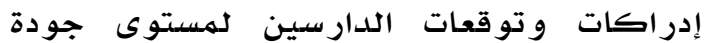
الخدمات التي تقدمها الكلية وهي على خمسة الته

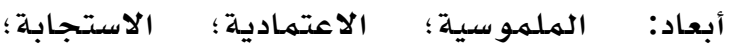
التوكيد/الثقة؛ التعاطف. التعاد.

وصف خصائص عينة الدراسة

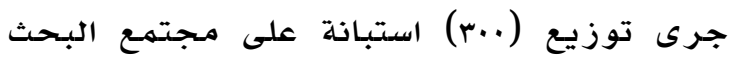

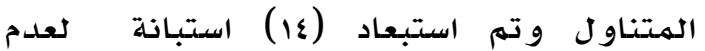

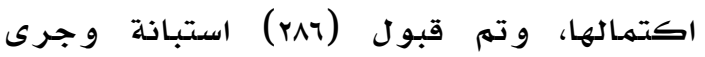
تحليلها، وجدول ا يوضح توزيع الاستبانات حسب فئات عينة البحثث. وجلول

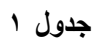
توزيع عينة الدراسة وفق بياناتهم الثخصية

\begin{tabular}{|c|c|c|c|}
\hline النسبة & العدد & التصنيف & المتغيرات \\
\hline$\varepsilon 9,$. & $1 \leqslant$. & ذكر & 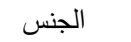 \\
\hline 01, & $1 \leq 7$ & أنثى & \\
\hline O^,. & 177 & برنامج البكالوريوس & المستوى \\
\hline$\leqslant r,$. & $\pi$. & برنامج بعد & التعليمي \\
\hline $1 \cdots, \cdot$ & rAT & & المجموع \\
\hline
\end{tabular}

سيتهم عرض النتائج وفقا لأسئلة الدراسـة كما يلي: هل توجد فروق ذات دلالة إحصائية عند مستوى

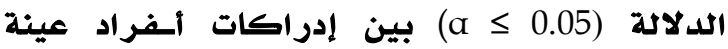
المطلوب. 
وظهر في متغير (الإمكانات المتاحة مناسبة و جذابة) ؛ بينهـا كان أقل فرق (-11, (.) قد ظهر

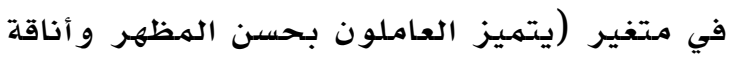

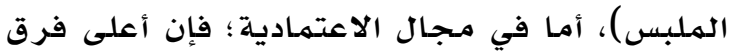
(1,§^-)

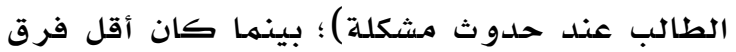

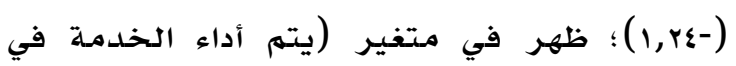

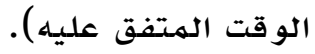

أما من حيث الفجوة بين الخدمة المدلدركة

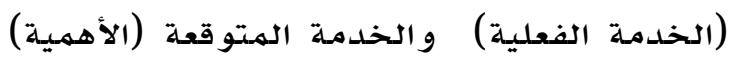
بحسب فقرات كل مجال، يتضح من خلال جدل جدول r أن هناك فجوة بين الخدمة الهتوقعة (الأهميلة)

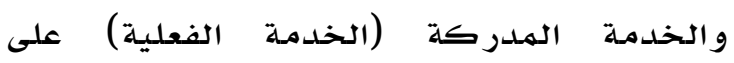

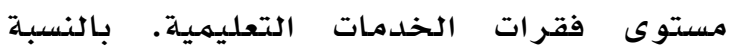
لعناصر مجال المـادية الملموسـة ؛ فإن تقييهم الدارسين لمستوى جودة الخدمهة التي تقدمها

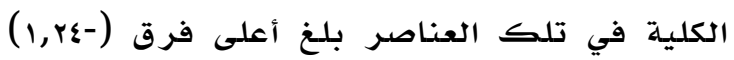
جدول r

من الدارسين لجودة الذذمة المدركة (الخدمة الفعلية) Pairedالمتوسطات الحسابية والانحرافات المعيارية ونتائج اختبار "ت" لدالة الفروق بين تقديرات مجموعتين مترابطتين والخدمة المتوقعة من الكلية بحسب المجالات وعناصر كل مجال

\begin{tabular}{|c|c|c|c|c|c|c|c|c|}
\hline \multirow{2}{*}{ 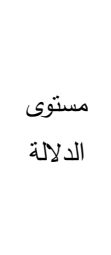 } & \multirow{2}{*}{ 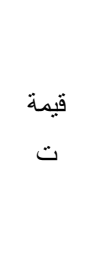 } & 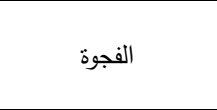 & \multicolumn{2}{|c|}{ 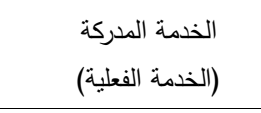 } & \multicolumn{2}{|c|}{ 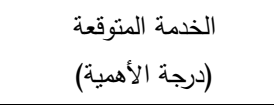 } & \multirow[b]{2}{*}{ 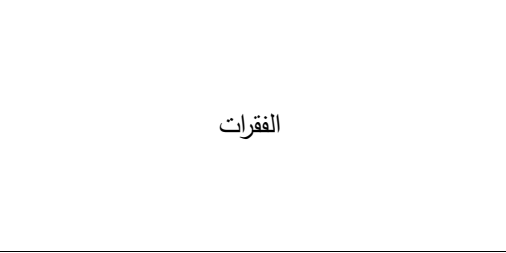 } & \multirow[b]{2}{*}{ s } \\
\hline & & $\begin{array}{l}\text { المنوسطات (المدرك } \\
\text { الفرق بين - المتوقع) }\end{array}$ & 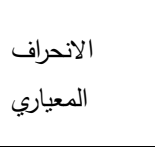 & الحسابي & 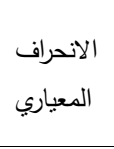 & الحسابي & & \\
\hline$* \cdot, \cdots$ & Ir,VA & $\cdot, \wedge r_{-}$ & $\cdot, \wedge$ & r, rی & $\cdot, \mathrm{V}$ & $\varepsilon, r$. & 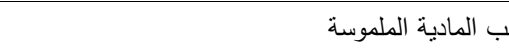 & 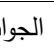 \\
\hline$* \cdot, \cdots$ & $1 r, \cdot \Lambda$ & $1,11-$ & $1, .9$ & $r, r \uparrow$ & $\cdot, \wedge \wedge$ & $\varepsilon, \varepsilon \vee$ & الأجهزة والمعدات في الكلية مسايرة للعصر وحديثة & 1 \\
\hline$* \cdot, \cdots$ & IT,OV & $1, r \leq-$ & I, & ५,१५ & $\cdot, 91$ & $\varepsilon, r$. & الإمكانات المتاحة مناسبة وجذابة & r \\
\hline$\cdot, 149$ & $1, \leq 9$ & $\cdot, 11$ & $\cdot, \wedge$ & $\varepsilon, \cdot r$ & 1,11 & $r, q 1$ & يتميز العاملون بحسن المظهر وأناقة الملبس & r \\
\hline$* \cdot, \cdots$ & IY,rV & $1,11-$ & 1,11 & r, r & $\cdot, 94$ & L & يتلاءم المكان مع طبيعة الخدمة المقدمة & $\varepsilon$ \\
\hline$*, \cdots$ & $I V, Y \leq$ & $1, r r_{-}$ & ( & $r, \cdot r$ & $\cdot, \wedge 4$ & $\varepsilon, r \varepsilon$ & 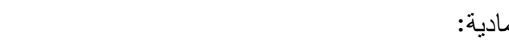 & الاعن المن \\
\hline$* \cdot, \cdots$ & $1 \leq, 1 V$ & $1, r V-$ & 1,17 & $r, 1$. & $\wedge 9, \mathrm{i}$ & $\varepsilon, r v$ & تكتمل الخدمة في الموعد المتفق عليه & $\circ$ \\
\hline$* \cdot, \cdots$ & 10,10 & $1, \varepsilon \wedge-$ & $1, Y 4$ & $r, 90$ & $\cdot, 99$ & $\varepsilon, \varepsilon r$ & تتعاطف الكلية مع الطالب عند حدوث مشكلة & 1 \\
\hline$* \cdot, \cdots$ & $1 \leqslant, 0 \leqslant$ & $1, \varepsilon r-$ & 1,10 & r,q & $\cdot, 91$ & $\varepsilon$, ro $_{0}$ & يتم تصحيح الأخطاء فور اكتثافها & v \\
\hline$* \cdot, \cdots$ & $M, \Sigma T$ & $1, r \leqslant-$ & 1,15 & $r, 1 \cdot$ & $\cdot, 9 \leqslant$ & $\varepsilon, \Gamma \varepsilon$ & يتم أداء الخدمة في الوقت الهتفق عليه & $\wedge$ \\
\hline$*, \cdots$ & $10, r$. & $1,17-$ & • & $r, 1 \cdot$ & $\cdot, \wedge 7$ & $\varepsilon, Y^{\top}$ & & 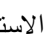 \\
\hline$* \cdot, \cdots$ & $1 \leq, r Y$ & $1, r{ }_{-}$ & 1,15 & r,q. & $\cdot, 99$ & $\varepsilon, Y \uparrow$ & الحصول على خدمة فورية & 9 \\
\hline$* \cdot, \cdots$ & $1 \Gamma, \cdot \varepsilon$ & $1,1-$ & $1, .9$ & $r, r q$ & $\cdot, 94$ & $\varepsilon, r q$ & الاستعداد الدائم لدى العاملين لمساعدة الطلبة & 1. \\
\hline$* \cdot, \cdots$ & $11, \mathrm{VV}$ & $1, \cdot 1-$ & 1,1 & $r, 1 \leq$ & $\cdot, 9 \vee$ & $\varepsilon, r_{r}$ & العاملون ليسوا مشغولين عن تلبية حاجة الطلبة & 11 \\
\hline$* \cdot, \cdots$ & $10, r$ & $1,17-$ & • & $r, 1 \cdot$ & $\cdot, \wedge \uparrow$ & $\varepsilon, Y \uparrow$ & 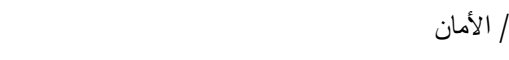 & 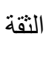 \\
\hline$* \cdot, \cdots$ & $\wedge, q r$ & $\cdot, \vee>-$ & $\cdot, 99$ & r,vo & $\cdot, 91$ & $\varepsilon, \leqslant 7$ & العاملون في الكلية أهل للثقة & ir \\
\hline$* \cdot, \cdots$ & $1 \cdot, r Y$ & $\cdot, \wedge \varepsilon-$ & $1, \cdot 9$ & rוtי & $\cdot, \wedge \vee$ & $\varepsilon, \varepsilon V$ & الكلية الإحساس بالأمسان عنــــالتعامـل مـع العـاملين في & ir \\
\hline$* \cdot, \cdots$ & $1 \cdot, \mathrm{VT}$ & $\cdot, \wedge r-$ & $1, \cdot 9$ & r,vr & $\cdot, \mathrm{VV}$ & $\{, 07$ & السلوك المهذب للعاملين & $1 \varepsilon$ \\
\hline$* \cdot, \cdots$ & 11,11 & $\cdot, 9 \leqslant-$ & $1, \cdot v$ & r,or & $\cdot, \wedge 1$ & $\varepsilon, \varepsilon \vee$ & العاملون لديهم المعلومات الأساسية & 10 \\
\hline$* \cdot, \cdots$ & $17, \mathrm{rV}$ & $1, r \wedge-$ & $1,+7$ & $r, 97$ & $\cdot, \wedge r$ & $\varepsilon, \Gamma \leqslant$ & & التعاد \\
\hline$* \cdot, \cdots$ & 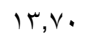 & $\cdot$, , १- & $1, r$ & $r, \cdot r$ & $\cdot, 9$ & $\varepsilon, r$ & الاهتمام الفردي من قبل الكلية بالطلبة & 17 \\
\hline$* \cdot, \cdots$ & $1 T, Y_{4}$ & 1,ro- & $1, r q$ & $r, \cdot r$ & $\cdot, 9$ & $\varepsilon, \Gamma \wedge$ & توفير ساعات ملائمة لظروف الطلبة & iv \\
\hline$* \cdot, \cdots$ & $10,9 \leq$ & $1, \cdot 7-$ & 1,19 & r,А & $\cdot, 9 \leqslant$ & $\varepsilon, \leqslant 7$ & وضع مصلحة الطالب في مقدة اهتمامات الكلية & 11 \\
\hline$* \cdot, \cdots$ & $1 T, \Sigma V$ & l, ז八- & $1, r r$ & $r, \wedge \wedge$ & $1, \cdot \varepsilon$ & $\varepsilon, Y_{\uparrow}$ & معرفة العاملين لاحتياجات الطلبة الخاصة & 19 \\
\hline$* \cdot, \cdots$ & IV,or & $1, \cdot 1-$ & $\cdot, V^{\top}$ & $r, r r$ & $\cdot, \mathrm{VY}$ & $\varepsilon, \Gamma$ & الدرجة الكلية & \\
\hline
\end{tabular}

قيمة (t) الجدولية عند مستوى (1) $\alpha \leq 0.01)($ : دال عند مستوى دلالة 
دلالة إحصائية بين استجابات عينة الدراسة حول

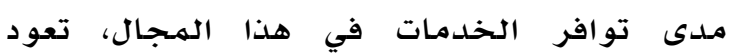
لاختالاف نوع العينة. أي أن الذكور والإناث

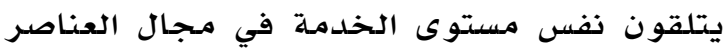

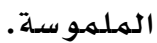

كما يتضح من جدول r أن قيهم (ت) للخدمة

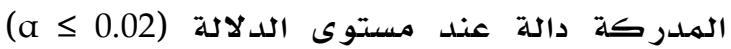
في المجالات: (الاعتمادية، الاستجابية، الأمان،

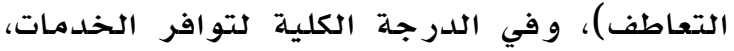
مما يشير إلى وجود فروق ذات دلالة إحصائية

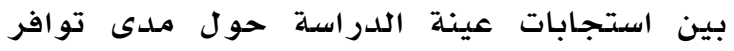

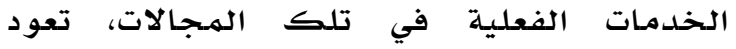

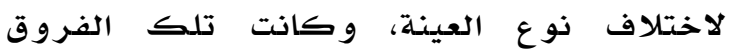
لصالح عينة الذكور. وهذا يعني أن الذكور يرون أن الخدمات التعليمية في تلك المجالات تقلدم لهم بصورة أفضل حاثلا عما هي عليه عند

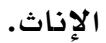

أما فيما يتعلق بتوقع الخدمة (درجة الأهمية)

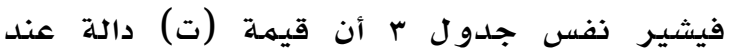

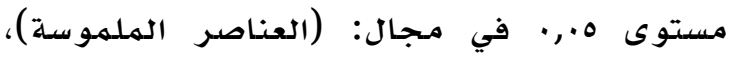
مـما يشير إلى وجود فروق (فجوة) ذات دلادية

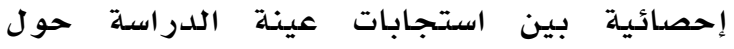

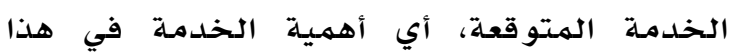

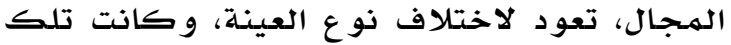

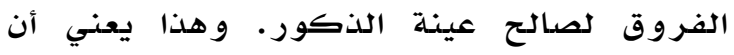

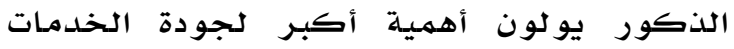
التعليمة مها هو عليه الأمر عند الإناث.

كما يتضح من جدول ب أن قـيم (ت) غيـر دالــة في المجـالات: (الاعتمـاديسة، الاسـتجابة، الأمسان،

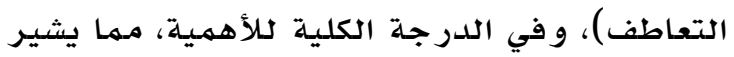
إلى عدم وجود فروق ذات دلادـة إحصدـائية بـين

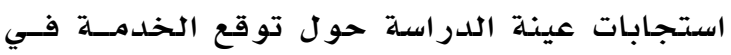

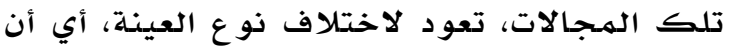
هنالك اتفاق بين الـذكور والإنـاث فـي توقعـات جودة الخدمة في تلك المسجالات من قبل الكلية.
أما في مجال الاستجابة؛ فإن أعلى فرق (-1, إ)

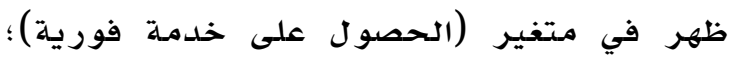
بينما كان أقل فرق (1,1)؛ ظهر في في متغير

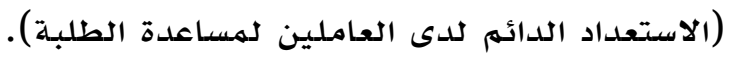

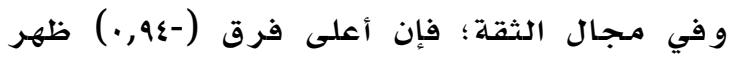

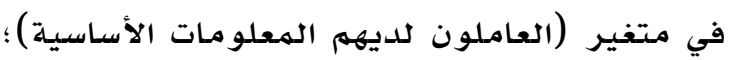
بينما كان أقل فرق (-VI,)؛ ظهر في متغير

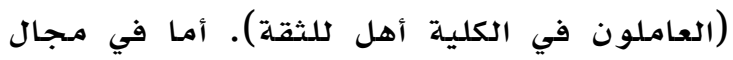

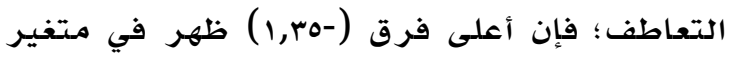

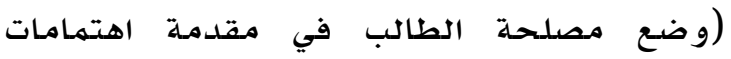

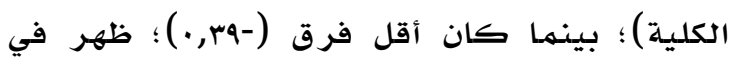
متغير (الاهتهمام الفردي من قبل الكلية بالطلبة). و باستخدام الاختبار الإحصائي (t-test) لبيان

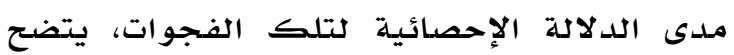

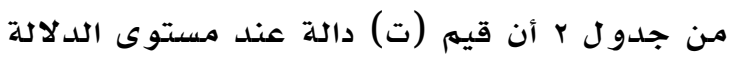

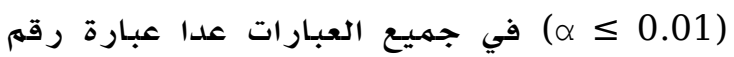

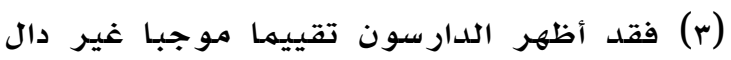

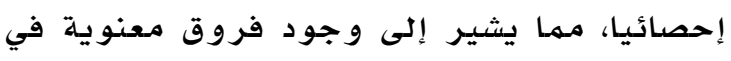

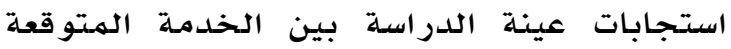

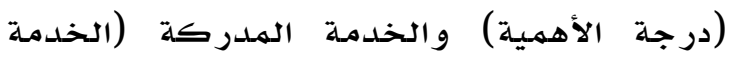

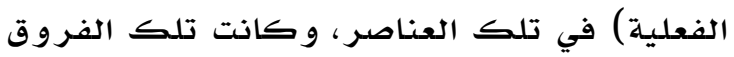
لصالح درجة الخدمـة الهتوقعة (درجة الأهميـة). كما يتضسح من جدول r أن قيمـة (ت) غير دالة

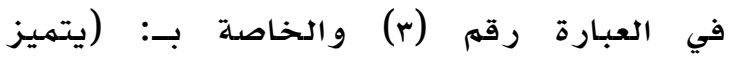

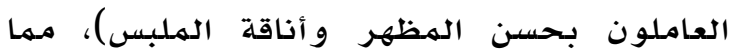
يشير إلى عدم وجود فروق ذات دلادة إحصدائية

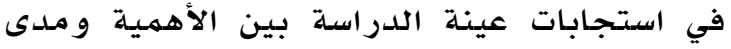
توافر هذا العنصر .

هل توجد فروق ذات دلالة إحصائية عند مستوى الدلالة (a 0.05 a الدارسين وتوقعاتهم لهذه الخدمة تعزى لمتغير الجنسو

جدول r يبين نتيجة الفروق في الخدمة

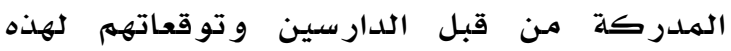

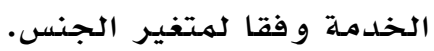
فيما يتعلق بالخدمة المدرركة، يتضسح من جدول r أن قيمة (ت) غير دالة في مجال: (العناصر

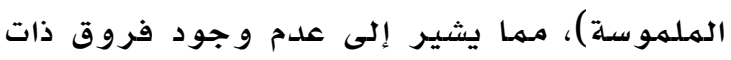




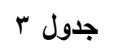

المتوسطات الحسابية والانحرافات المعيارية ونتائج اختبار "ت" للالة الفروق بين تقديرات الدارسين لجودة الخدمة الددركة (الذذمة الفعلية) والمتوقعة من

\begin{tabular}{|c|c|c|c|c|c|c|c|c|}
\hline & & & & بعا لم & & & & \\
\hline \multirow[t]{2}{*}{ مستوى الدلالة } & \multirow[t]{2}{*}{ ت المحسوبة } & \multirow{2}{*}{ الفتوسطات } & \multicolumn{2}{|c|}{ الإناث (•؛ () } & \multirow{2}{*}{\multicolumn{2}{|c|}{ الذكور ( آس ا) }} & \multirow[t]{2}{*}{ الفجوة } & \multirow[t]{2}{*}{ المجالات } \\
\hline & & & الانحراف & المتوسط & & & & \\
\hline$\cdot, \cdot \wedge \wedge$ & $1, \times 1$ & $\cdot, 17$ & $\cdot, \vee \wedge$ & $r, r q$ & $\cdot, \lambda 1$ & $r, \varepsilon 0$ & الإدراك & الجوانب المادية \\
\hline$\because \cdot, \cdot r r$ & $r, r)$ & $\cdot, r_{1}$ & $\cdot, \vee \vee q$ & $\varepsilon, .9$ & $\cdot, \mathrm{V}$ & $\varepsilon, r$. & النوقع & الملموسة \\
\hline$*$ & $\varepsilon, 0$. & $\cdot, \varepsilon V$ & $\cdot, 9$. & $r, Y \wedge$ & $\cdot, \wedge 9$ & r, ro & الإدراك & الاعتمادية \\
\hline$\cdot, T \leqslant Y$ & $\cdot, \varepsilon \vee$ & $\cdot, .0$ & $\cdot, \wedge T$ & $\varepsilon, \Gamma$ & $\cdot, \wedge \vee$ & $\varepsilon, r 4$ & التوقع & \\
\hline$*$ & $\varepsilon, r_{1}$ & $\cdot, \leqslant 0$ & $\cdot, 97$ & Y,AT & $\cdot, \wedge 7$ & $r, r$ & الإدراك & الاستجابة \\
\hline ודז,• & $\cdot, 91$ & $\cdot, 1$ & $\cdot, \wedge \vee$ & $\varepsilon, r$. & $\cdot, \wedge T$ & $\varepsilon, \Gamma$ & التوقع & \\
\hline$*, \ldots$ & $\varepsilon, 0$ r & $\cdot, \leqslant 7$ & $\cdot, \wedge \Lambda$ & $r, \varepsilon$. & $\cdot, \lambda r$ & r,Aт & الإدراك & السلامة والأمان \\
\hline$\cdot, \Pi \backslash V$ & $1, \cdots$ & $\cdot, \cdot 9$ & $\cdot, \vee V$ & $\varepsilon, \Gamma q$ & $\cdot, \vee \wedge$ & $\varepsilon, \varepsilon \wedge$ & التوقع & \\
\hline$*, \ldots$ & $\{, 0\}$ & $\cdot, 00$ & $1, .7$ & $r, T V$ & $\cdot, 91$ & $r, r r$ & الإدراك & التعاطف \\
\hline$\cdot, r \leq \Lambda$ & $\cdot, 9 \leq$ & $\cdot, 1$ & $\cdot, \wedge$ & $\varepsilon, \Gamma \wedge$ & $\cdot, \wedge \wedge$ & $\varepsilon, \Upsilon \wedge$ & التوقع & \\
\hline$*, \ldots$ & $\varepsilon, \vee q$ & $1, \varepsilon r$ & $\cdot, v r$ & $r, \cdot 1$ & $\cdot, v r$ & $r, \varepsilon r$ & الإدراك & الكلي \\
\hline$\cdot, \leqslant r_{0}$ & $\cdot, \wedge$. & $\cdot, \cdot V$ & $\cdot, \mathrm{V} r$ & $\varepsilon, r V$ & $\cdot, \mathrm{VT}$ & $\varepsilon, \Gamma \varepsilon$ & التوقع & \\
\hline
\end{tabular}

جدول ؛

المتوسطات الحسابية والانحرافات المعيارية ونتائج اختبار "ت" لالالة الفروق بين تقديرات الدارسين لجودة الخدمة المدركة (الفعلية) والمتوقعة من الكلية تبعا لمتنير المستوى التعليمي لبكي

\begin{tabular}{|c|c|c|c|c|c|c|c|c|}
\hline \multirow[t]{2}{*}{ مستوى الدلالة } & \multirow[t]{2}{*}{ ت المحسوبة } & \multirow{2}{*}{ الفتوسطات } & \multicolumn{2}{|c|}{ بعد البكالوريوس (1) I I) } & \multicolumn{2}{|c|}{ البكالوريوس (101) } & \multirow[t]{2}{*}{ الفجوة } & \multirow[t]{2}{*}{ المجالات } \\
\hline & & & الانحراف & المتوسط & الانحراف & المتوسط & & \\
\hline$\cdot, r \leqslant 0$ & $1,1 \mathrm{~V}$ & 1,11 & $\cdot, 79$ & $r, \varepsilon r$ & $\cdot, A V$ & $r, r r$ & الإدراك & الجوانب المادية \\
\hline$\cdot, .79$ & l, ג & $\cdot, 17$ & $\cdot, 7 \varepsilon$ & $\varepsilon, \Upsilon_{9}$ & $\cdot, 10$ & $\varepsilon, 1 \pi$ & التوقع & الملموسة \\
\hline$\cdot, r M$ & 1, ro & $\cdot, 1 \leqslant$ & $\cdot, 9$ & r, 9 r & $\cdot, 9 \leqslant$ & $r, \cdot v$ & ال الإدراك & الاعتمادية \\
\hline$\because \cdot, \cdot, 1 \leq$ & $r, \varepsilon \wedge$ & •, Y4 & $\cdot, \vee \vee 9$ & $\varepsilon, \varepsilon \wedge$ & $\cdot, 9$ & $\varepsilon, r r$ & التوقع & \\
\hline •,YIV & $1, r \varepsilon$ & $\cdot, 1 \leqslant$ & • & $r, 17$ & $1, \cdot 1$ & $r, \cdot r$ & ال الإدراك & الاستجابة \\
\hline$\cdot, .01$ & $1,9$. & $\cdot, 19$ & $\cdot, V Y$ & צ & $\cdot, 90$ & $\varepsilon, I V$ & التوقع & \\
\hline$* \cdot, \cdot 10$ & $r, \leqslant 0$ & • & $\cdot, \wedge$. & r,vA & •,9 & r,or & ال الإدراك & السلامة \\
\hline$\cdot, \ldots$ & $r, A r$ & •, ro & $\cdot, 71$ & $\varepsilon, 0 \wedge$ & $\cdot, \wedge 4$ & 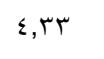 & النوقع & و الأمان \\
\hline 每 & $\cdot, r \varepsilon$ & $\cdot, \cdot r$ & $1, \cdots$ & r,१ & 1,1 & r.१५ & ال الإدراك & التعاطف \\
\hline .,Or & $\cdot, 7 \varepsilon$ & $\cdot, \cdot V$ & $\cdot, \wedge 1$ & $\varepsilon, r v$ & $\cdot, \wedge 4$ & $\varepsilon, r$. & النوقع & \\
\hline$\cdot, \Sigma Y \wedge$ & $\cdot, \vee 9$ & $\cdot, \cdot V$ & $\cdot, 7 \wedge$ & r, ro & $\cdot, \wedge 1$ & $r, \curlywedge \wedge$ & ال الإدراك & 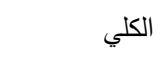 \\
\hline$\because, ., r 1$ & r,IV & $\cdot, 11$ & זי, & $\varepsilon, \varepsilon 1$ & $\cdot, \vee 9$ & $\varepsilon, r$ & النوقع & \\
\hline
\end{tabular}

دال عند مستوى ( 1 (

لأفراد العينة. وهذا يعني أن جميع الدارسين في

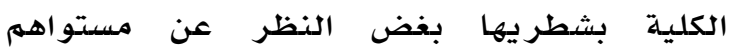

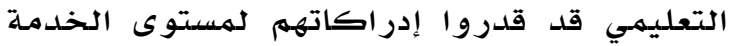

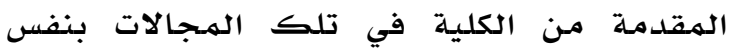

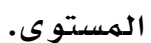

كما يتضح من جدول

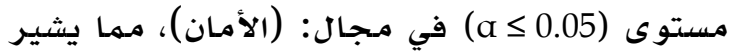
إلى وجود فروق ذات دلالة إحصائية بين
فيما يتعلق بدلالة الفروق حول الخدمة

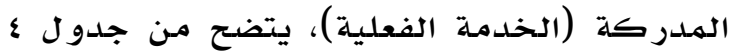

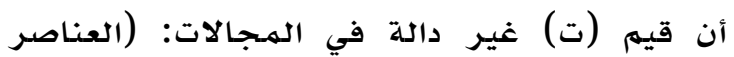

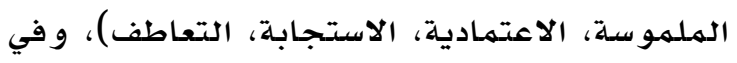

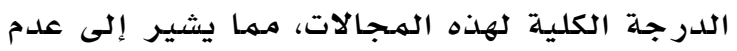
وجود فروق ذات دلالة إحصائية بين استجابات

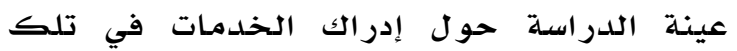

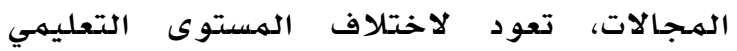


التعليمية لا تقدم للطلاب بالشكل الذي يتوقعه الطلاب مـن مؤسساتهم التعليميلة. أهم الاستنتاجات

إن جودة الخدمات التعليمة المقدمـة من قبل

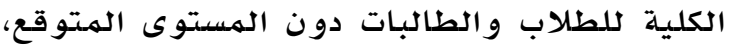
فقد بينت نتائج الدراسة أن هناك فجوة دالة إحصائيا بين الخدمة الفعلية الهقدمة للدارسين

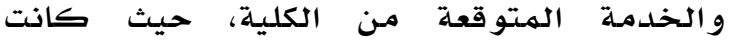
الخدمة الفعلية المقدمة للدارسين أقل مستوى المئو

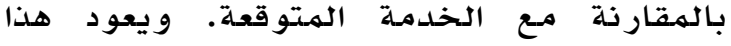

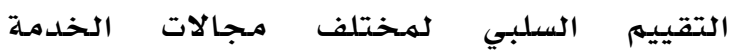

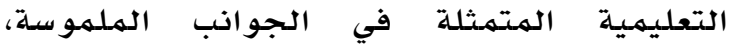

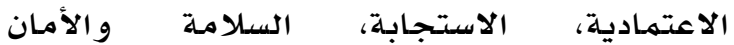
و التعاطف, ويمكن إرجاع مسببـات هذه الفجوات

أ. غموض الدور الوظيفي لدى الموظفين. ب. صراع الأدوار للدى الموظفين. ج. عدم مـلاءمـة العاملين للوظيفة. د. ضعف التكنولوجيا المستخدمة للوظيفة. ه. نظام رقابي غير مـانمه. و. الافتقار إلى العمل بنظام الفريق. ز · ضعف الإشر اف على الموظفين. التوصيات

بناء على نتائج الدراسـة يوصي الباحثان القيام بالآتي:

ا. العهل على الارتقاء بمستوى جودة الخدمـة

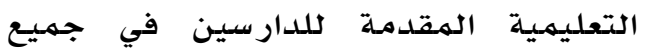
عناصر مجالات الخدمة و والتي أظهر

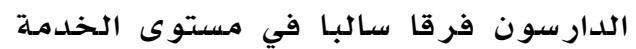
فيها و لاسيما التي كانت أكثر تدنيا مـن وجهة نظر الطلاب أو الطالبات، أو أو أوسئا

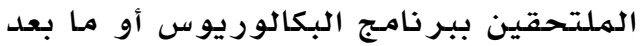

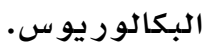

r. ضدورة تكرار قياس مستوى جودة الخدمة بصورة منتظمهة للوقوف على مدى التحسن والتطور في مستوى جودة تلك الخدمات
استجابات عينة الدراسلة حول إدراكاتهم لمستوى

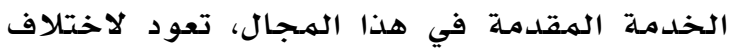

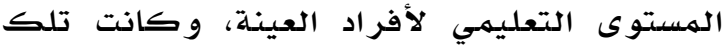

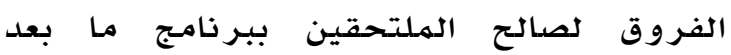

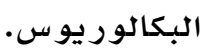

أما فيما يتعلق بدلالة الفروق حول توقع الخدمة الخدة

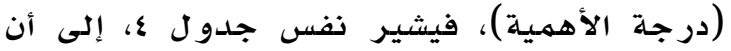
قيم (ت) غير دالة في المجالات: (العناصر

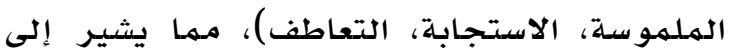

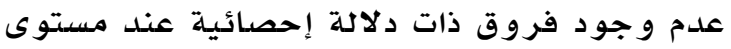

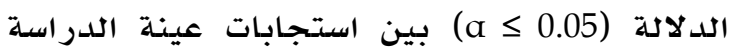

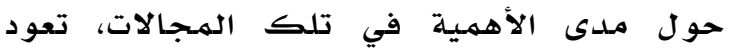

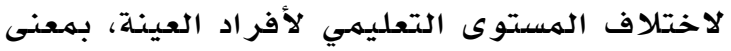
أن جميع الدارسين بغض النظر عن مستواهم

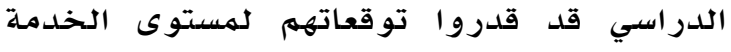

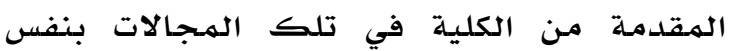
المستوى.

كما يتضع من جلدول \& أن قيه (ت) دالة عند مستوى (a 0.05 a

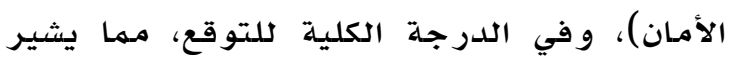

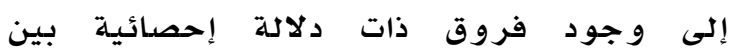

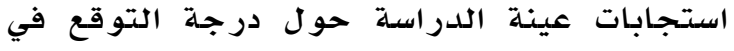
تلك المجالات، تعود لاختلاف الهستوى التعليهي لأفراد العينة، وكانت تلك الفروق لصالح الملتحقين ببر نامـج ما بعد البكالوريوسلوسل أما فيما يتعلق بدلالة الفروق بين الهتوقع

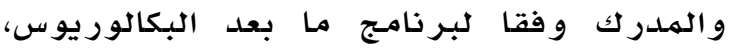
يشير جدول ع، أن قيم (ت) دالة مستوى الدلالة

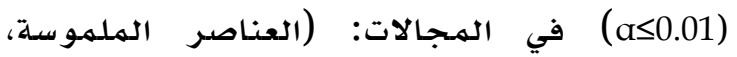
الاعتمادية، الاستجابة، الأمان، التعاطف)، ولهي الدرجة الكلية للهمجالات، مها يشير إلى وجودات فروق ذات دلالة إحصائية في استجابات عينة

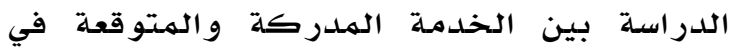
تلك المجالات، وكانت تلك الفروق لصالح الخدمة الهتوقعة أي إلى أهمية تلك الهـا الخدمة. و لقد اتفقت نتائج الدراسـة الحالية مـع دراسـة

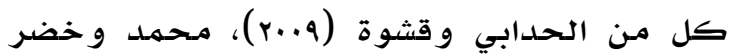

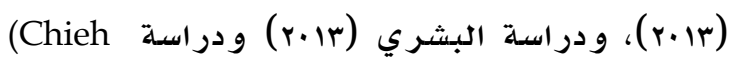
Hsiung Wan, (2009). 


\section{المستوى العالهي. مجلة العلوم الإنسانية،

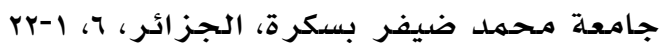

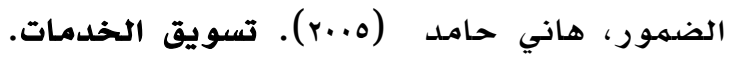 دار وائل للنشر، الطبعة الثالثة: عمان.

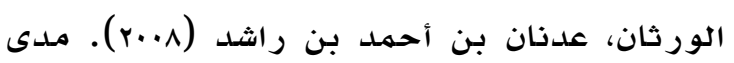

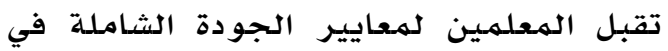

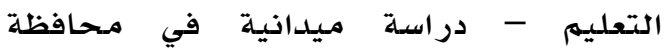

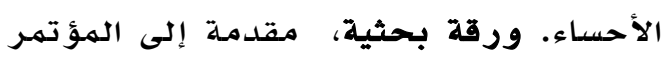

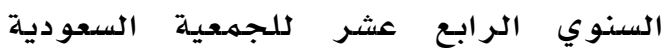
للعلوم النفسية و التر بوية (جستن)، القصيهم. الهنيع، الجوهرة بنت عبد الرحمن (rا.r). تقييم

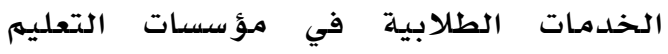

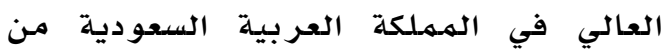
وجهة نظر الطالبات. مجلة المنهج العلمي والسلو ك، مصر ، باه

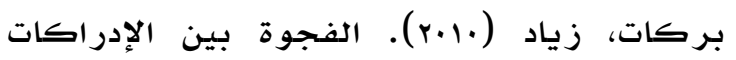

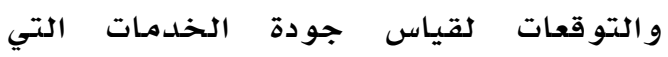

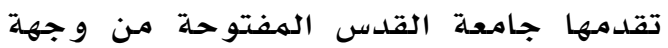

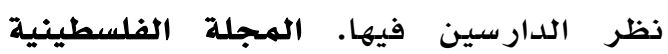

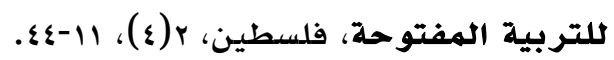

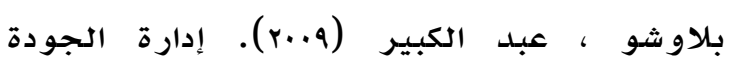

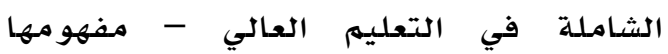
و مراحل تطبيقها. ورقة عمل مقدمة إملى إلى الندوة العلمية حول جودة التهل التعليهم العالي

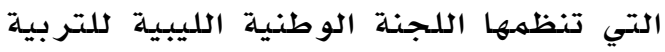

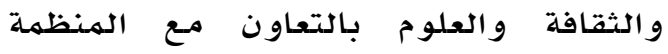

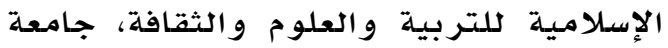

$$
\text { الفاتح - طر ابلس. الاسلس مئس }
$$

تيغيزة، محمد بوزيان (^) (r). نظرية الصدق

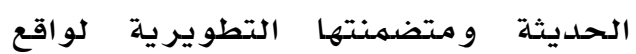
القياس. ندوة علم النفس : علهم النفس

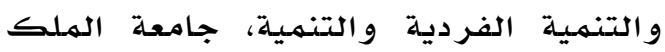

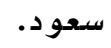

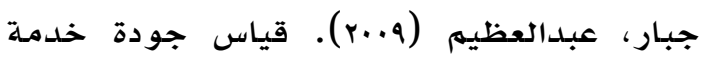

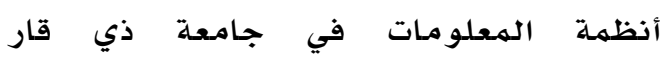
باستخدام مقياس الفجوة بين الإدراكات

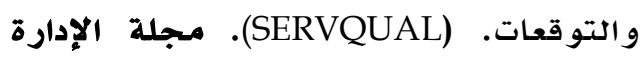

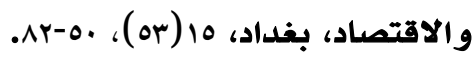

الهقدمة من قبل الكلية بشطريها (الذكور

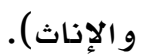
r. ضرورة تبني إدارة الكلية (بشطريها) جودة

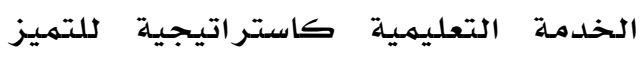

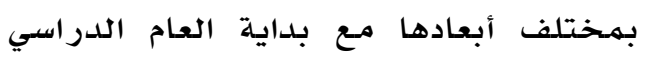

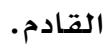

\section{المراجع}

\section{References}

البشري، سهام بنت سالم بن حمدان (rا.r).

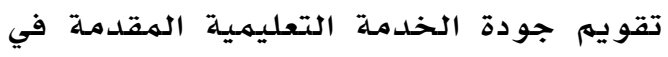

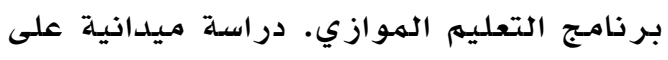

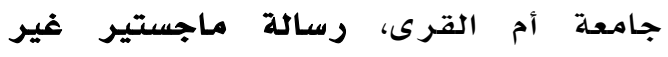

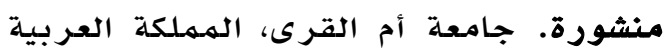

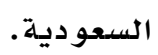

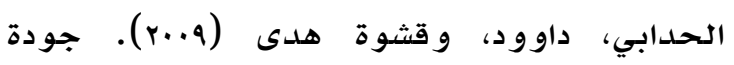

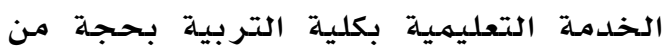

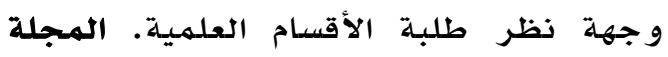

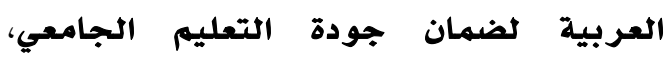
الأردن، ع، العزية لونهان

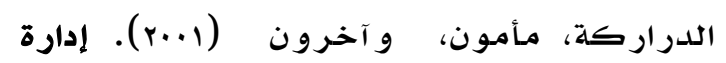
الجودة الشاملة. دار صفاء للنشر والتوزيع: عمان.

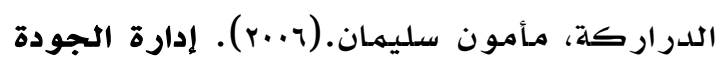

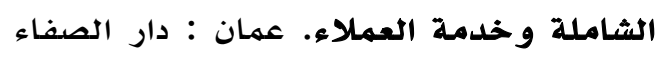

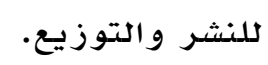

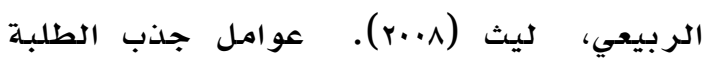

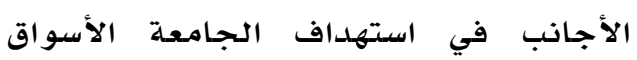

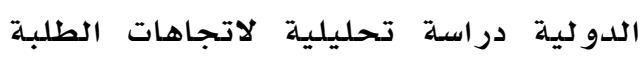

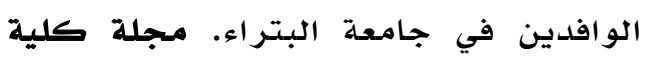

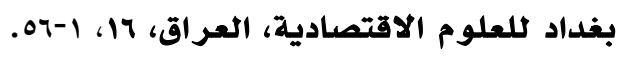

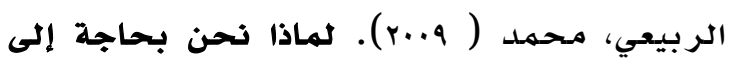
نظام لضمان الجودة في الجامعات. تاريخ

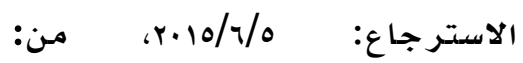
.http://www.inciraq.com/

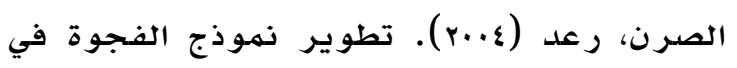

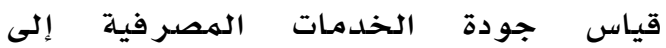




\section{حالة برنامـج الجامعة الإسـلامية بغزة. مـجلة

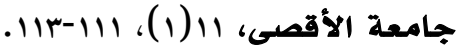

Abraham, J. K. \& Lawson, T.A. (2006).

Clarifying the dimensions of four concepts of quality. Theoretical Issues in Ergonomics Science, 9(1), 73-94.

Berry, L., et., al., (1991). Perceived Service Quality as a Customer -Based Performance Measure: An Empirical Examination of Organizational Barriers Using an Extended Service Quality Model. Human Resource Management, 30 (3), 312337.

Chieh Hsiung Wan, (2009). A study of the relationship between student and Faculty satisfaction of service quality within Asi University in Taiwan, A dissertation submitted doctor of education.

Eastwood, D. B., Brooker, J. R. \& Smith, J. D. (2005). Developing Marketing Strategies for green Grocers: An Application of SERVQUAL. Agribusiness, 21(1), 81-96.

Francis Hoh Yin Kwei, (2005). An Exploratory Study in Service Quality at Selected South African Vehicle Dealerships. A research report submitted to the Faculty of Engineering and the Built Environment. University of the Witwatersrand, Johannesburg, in partial fulfillment of the requirements for the degree of Master of Science in Engineering. Johannesburg.

Hoffman, K. Douglas, Bateson, John. E.G (2011). Services Marketing. Concepts, Strategies, E Cases, South-Westeren. Cengage Learning, U.S.A.

Kadhim, R. J., Taqi, B. S. M., Shuaibu, B. M. (2012). Development a Prototype of Academic Performance Among University Students. International Journal of Independent Research Studies, 1(1), 39-49.

Kolcinski, John, (2002), "Evaluation of success and failure factors and criteria in implementation of total quality management principles in administration at selected institution of higher education, Winona State University.

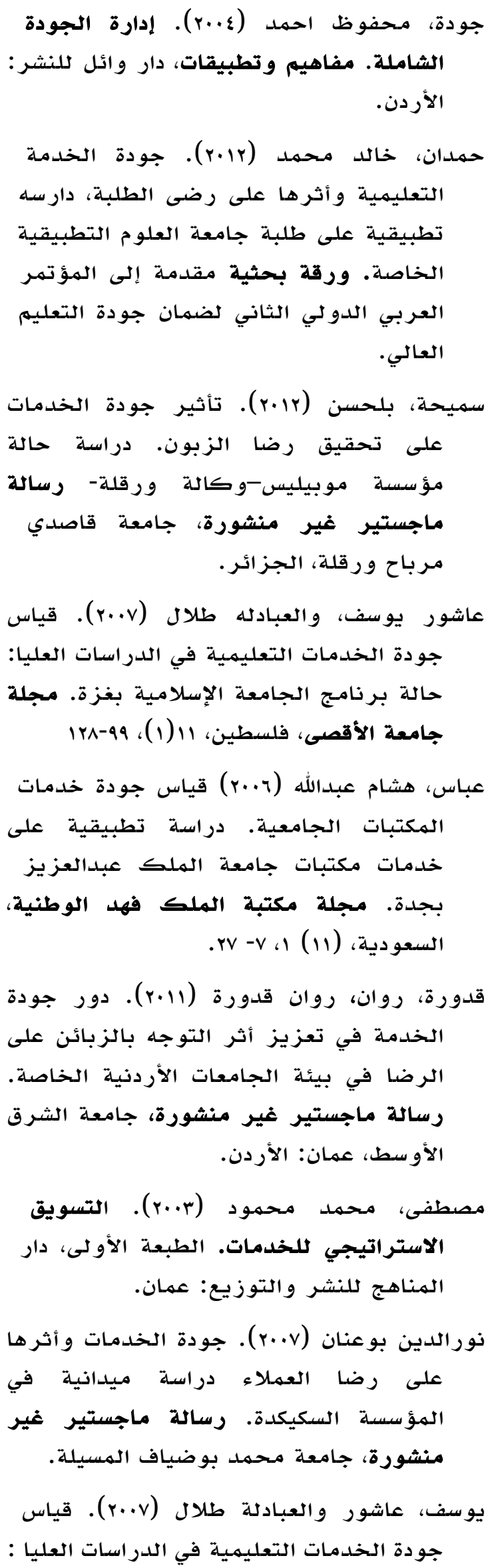


Kotler, P. (1997). Marketing management, Analysis, Planning implementation and control, prentice- Hall of India, New Delhi

Kotler, P. (2000). Marketing management. 11th edition, prentice Hall, New Jersey.

Krajewski, Lee J. \& Larry P. (2000). Operations management: Strategy and Analysis, Don Mills. Ontario New York: Addison Wesley publishing Company .

Kumar, M., Kee, F. T. \& Manshor, A. (2009). Determining the relative importance of critical factors in delivering service quality of banks; An application of Krajewski.

Lovelock, C. (2002). Services Marketing. New Jersey: Prentice-Hall International.

Lewis, B. R. \& Mitchell, V.W. (1990). Defining and measuring the quality of customer service. Marketing Intelligence and Planning, 8(6), 11-17

Lenn, M. (2000). Higher Education and the Global Marketplace: A Practical Guide to Sustaining Quality. On the Horizon, 8(5), 7-10.

Otávio J. O. (2011). Adaptation and application of the SERVQUAL scale in higher education. POMS 20th Annual Conference Orlando, Florida U.S.A. May 1 to May 4, 2009, Nutrition E Food Science, 33 (4), 165-172.

O'Neill, M. (2000). The Role of Perception in Disconfirmation Models of Service quality. Measuring Business Excellence. 4(2), pp. 4659.

Otávio J. O. (2011). Adaptation and application of the SERVQUAL scale in higher education. POMS 20th Annual Conference. Orlando, Florida U.S.A. May 1 to May 4, 2009.

Palmer, A. \& Cole, C. (1995). Services Marketing: Principles and Practice. PrenticeHall, Englewood Cliffs, NJ.

Parasuraman, A., Zeithaml, V. A., \& Berry, L. L. (1985). A conceptual model of service quality and its implications for future research. Journal of Marketing, 49, 41-50.

Parasuraman, A., Zeithaml, V. A., \& Berry, L. L. (1988). SERVQUAL: A multiple-item scale for measuring consumer perceptions
Parasuraman, A., Zeithaml, Valerie A. \& Berry, Leonard.L. (1985). A conceptual model of service quality and its implications for future research. Journal of Marketing, 49, 41-50.

Shank, M. D., Walker, M. \& Hayes, T. (1995). Understanding professional service expectations: Do we know what our students expect in a quality education. Journal of Professional Services Marketing, 13(1), 71-89. 